\title{
Mapping collaboration networks in Talent Management research
}

\author{
Eva Gallardo-Gallardo, Universitat Politècnica de Catalunya-BarcelonaTech \\ Liliana Arroyo Moliner, Universitat de Barcelona \\ Pedro Gallo, Universitat de Barcelona
}

Purpose (100 words): Despite the popularity of talent management (TM), very little has been published on the community of scholars that contribute to the knowledge base of the field. The aim of this paper is to disclose the dynamics in TM research through a detailed analysis of its evolving collaboration networks (i.e., research communities) in order to identify key authors and major topics covered.

Design/Methodology/approach (100 words): A total of 225 co-authored articles published on TM from 2001 to May 2016 were retrieved from the Web of Science and Scopus and then analyzed and mapped using Social Network Analysis methods.

Findings (100 words): We identified two major scientific communities (one of 63 authors and the other one of 24 authors). Both communities not only have different characteristics and structure, but also focus on different topics. We identified key players within each community and we offer a dynamic view on the main topics studied.

Research implications: Our findings offer evidence on how collaborations among researchers shape the debates on the field. This can assist in drafting adequate strategies (at individual and discipline level) so as to help consolidate the field by encouraging new associations both in terms of actors involved and topics covered. Our study also offers a promising perspective for further using bibliometrics and social network analysis in TM research.

Practical implications: This article may help practitioners and newcomers to the field to rapidly identify key players and main topics studied in TM field. It may assist academic institutions and journal editorial teams in better assessing and identifying key scholars in this field.

Originality: This paper offers the first analysis of TM collaborative research networks.

Keywords: Talent Management; Social Network Analysis; Science mapping; Research communities; Co-authorship; Keywords;

Article classification: General review 


\section{Introduction}

We can posit that our knowledge of Talent management (TM) has its origins in the perceptions of a concrete business reality. Indeed, it is commonly accepted that all started when in 1997 a group of McKinsey consultants coined the expression 'war for talent' and expressed great concern about the supply of executive talent with pressing issues faced by the organizations in attracting and retaining key staff (Chambers et al., 1998). In 2001, these same consultants published an extended version of the report in a book called 'The War for Talent' (Michaels et al., 2001). This book was not only a bestseller, but also it has become widely cited as a seminal work in TM literature. The assumption underlying their work, based on nearly 13,000 interviews with managers of large and medium enterprises, was that, at least, US organizations were fighting a 'war' for executive talent. They postulated that a fundamental belief in the importance of talent is needed to achieve organizational excellence. In short, only those companies that managed to develop a talent mind-set, have the 'best and the brightest' (i.e., the talent) and get rid of low-performing employees were to succeed, which was interpreted as 'TM has a positive impact on business performance'. Since then, there has been a 'wave' of consultancy reports placing strong emphasis on the role of TM in businesses success (McDonnell et al., 2017). However, there was (and still is) little empirical evidence of the link between TM and organizational performance (see Collings, 2015).

In a recent work focused on tracing the cultural evolution of the TM concept, Swailes (2016), postulates that, although "McKinsey's role in the sociogenesis of TM should not be underestimated given its long-standing influence over corporate America" (p. 8), the birth point of TM was a few years before their report when US companies and large government offices were implementing changes in their programs in order to focus on their competitive but overlooked weapon: their talent. Recognizing the talent imperative was seen, indeed, as a strategic inflexion point for American corporations, and TM was positively related to business performance. According to Cappelli and Keller (2014) the notion of TM, and specifically of internal talent development, is associated with the rise of large corporations in the 1950s. During the post-World War II organizations' senior managers and executives demand exceeded the supply, creating an unprecedented talent shortage and forcing organizations to develop an internal supply of talent (Cappelli, 2010). However, during the economic downturn in the 1970s only very large American companies were able to maintain the 'growing talent from within' model, and the 'just-in-time' model based on external hiring started to expand (Cappelli, 2008). At this point, there is no doubt that the origins of TM can 
be located in United States, and within a specific context: large corporations (mostly, multinationals). Moreover, it cannot be neglected that practitioners and consultants led TM in its origins. Let us briefly analyse the consequences of these facts.

Academic research in TM has been accused of being 'lagging behind business' (Al Ariss et al., 2014b; Cascio and Boudreau, 2016). Indeed, for many years there has been a gap between minuscule academic interest and widespread practitioner interest in TM, which should not be surprising since TM emerged as a 'hot topic' in human resource practice. In fact, in 2006, Lewis and Heckman, in what is considered another seminal work in the field, offered the first in-depth literature review on the topic grounding on practitioner-oriented publications, since, at that time, they 'host most of the discussions regarding TM' (p. 139). Two years later, Reilly (2008) highlighted that TM had not been taken as seriously as it should in academic literature, and that is that few academic publications on the topic can be found before 2008 (Gallardo-Gallardo et al., 2015; McDonnell et al., 2017). According to Gallardo-Gallardo et al. (2013), the conceptual and theoretical confusion regarding the construct of TM can be attributed in part to the fact that most of the literature of the field has been practitioner-or consultancy-based. However, since then, there has been an escalating scholarly interest in the topic aiming to help advancing the field. Indeed, TM is considered to be one of the fastest growing areas of academic work in the management field over recent decades (Collings et al., 2015b). Recent literature reviews (Gallardo-Gallardo and Thunnissen, 2016; Gallardo-Gallardo et al., 2015; Thunnissen et al., 2013; McDonnell et al., 2017) offer complementary views on the breadth of TM research, some of them combining quantitative and qualitative approaches. Despite their undeniable value for evaluating the state of the art of TM research and for guiding discussion about its future development, they do not offer an explanation of the social organization of the field that is inextricably intertwined with the field intellectual development (see Vogel, 2012). Hence, a proper analysis of the social construction of the field (i.e., its social networks or scientific communities) is needed to provide further insight of the intellectual development of TM as a discipline.

Locating the origins of TM in large companies of North America, probably explains why most of the first publications on TM were US-centric and focused on multinationals (e.g., Collings et al., 2011b; Powell et al., 2013), and why there is a strong body of US affiliated scholars publishing in the field (McDonnell et al., 2017). However, more and more, there appears to be a strong network of European scholars operating (Gallardo-Gallardo et al., 2015; McDonnell et al., 2017). As the topic has grabbed non-US academics' attraction, 
primary research was also undertaken in other countries. In their recent review of the TM empirical literature, Gallardo-Gallardo and Thunnissen (2016), found that $40 \%$ of the articles were based on European countries, and there were more studies from Asian countries than from North America. So, at present, and in their own words: 'earlier claims of the US-centric nature of TM research seem exaggerated' (p. 40). What is also interesting is the reflection they made about authorship and the region of data collection. These authors state that whereas researchers from Europe, Australia, Middle East, South Africa and USA or Canada conduct the studies in their own region, those studies based on Asian countries were carried out by people from outside the region, or by people from the region in collaboration with people from developed countries. In fact, they conclude that collaboration (largely international) in the field is the norm rather than the exception, and that there is a group of Western scholars (mainly, from Anglo-Saxon countries) that act as a reference group. Both, collaboration networks and this 'core of experts' seem to play an important role in TM research accomplishments and dynamics. A deep insight into these international and national co-authorship relations helps us to better understand the complexity and heterogeneity of the discipline, to somehow locate the knowledge of the field, and to better appraise the roles of key actors in the network.

To fully understand a scientific domain, it is important to depict how scientists are formally or informally tied together, that is, to identify the so-called 'invisible colleges' (Gherardini \& Nucciotti, 2017; Vogel, 2012). Zuccala (2006) defines invisible colleges as "a set of interacting scholars or scientists who share similar research interests concerning a subject specialty, who often produce publications relevant to this topic and who communicate both formally and informally with one another to work towards meaningful goals in the subject, even though they may belong to geographically distant research affiliates" (p. 155). In fact, one of the factors that served Gallardo-Gallardo et al. (2015) in determining the growth stage of the TM phenomenon has been the existence of a 'core' scientific community (i.e., a group of scholars who interact and who are familiar with each other's work) that acts as a reference group to new entrants to the field. Further, according to Sarafoglou and Paelinck (2008), in a mature stage of the phenomenon, these scholars may also establish new associations. Thus, a proper analysis of collaboration in TM research would also help to clarify the evolution stage of the field.

A research community can deal with several topics, and different collaboration groups can study a given topic. Indeed, research topics and communities are not disconnected from each other. Quite on the contrary, they are interwoven and co-evolving (Yan et al., 2012). It 
is therefore necessary to integrate the study of communities and topic identification to understand the dynamics of interactions between themes and actors (Yan et al., 2012). Knowledge advancement is a communitarian process, and the analysis of such process goes hand by hand with the study of scientists' research interests (Gherardini \& Nucciotti, 2017). To this end, keywords analysis could help us identify highly popular topics and to better understand the evolution of research subjects and trends within a discipline (see, Zhang et al., 2016), since they reflect the core contents of a paper according to their authors. Indeed, topics develop and evolve dynamically (Upham \& Small, 2010) and keyword analysis could shed some light in the identification of hot topic themes in the domain, their origin and evolution through time.

This article seeks to complement previous literature reviews by means of: (i) mapping scientific communities in TM research through a detailed analysis of its evolving collaboration networks, (ii) identifying key players and analyzing the structure and nature of research communities, and (iii) disclosing the most frequent topics that attracted scientific interest. Focusing on co-authorship data and by means of Social Network Analysis (from now on SNA) this article is the first to offer a comprehensive picture of the relationships among researchers in the field. Specifically, we aim to answer the following research questions: What is the extent and nature of collaboration in TM research? Which are the key players? How do they gather into invisible colleges? Which are the main topics of research within the field? What is the relationship between topics and communities in TM research? Please, note that the nature of SNA methodologies is rather more exploratory than conclusive as causal relations cannot be established. Moreover, and as outlined below, performing a co-citation analysis would help enriching the explanation of the topics studied within the field, as well as providing an explanation of the intellectual structure of the field.

The article is structured as follows. We begin by discussing the methods used to collect and analyse the data. We then present, and show the results of our study. We conclude with a discussion of the implications of our findings and we offer ideas on future research.

\section{Methodology}

In order to map scientific networks in TM and provide evidence of collaborations we have made use of co-author analysis (see Zupic \& Cater, 2015). Further, we used SNA as the main analytical framework (for an introduction, see Wasserman and Faust, 1994) placing our 
focus on displaying the core networks in the field and the main topics studied. In this respect we have followed a four-step approach.

\section{Step 1: Data selection}

In agreement with a common practice in co-authorship studies, we have confined our analysis to publications in academic journals (e.g., Henriksen, 2016; Vogel, 2012), particularly to international peer reviewed journals since they can be considered to represent leadership scholarship. We used Web of Science and Scopus to identify relevant articles for our analysis. In line with previous literature reviews (e.g. Gallardo-Gallardo et al. 2015; Gallardo-Gallardo and Thunnissen 2016; McDonnell et al., 2017), we used the term "talent management" as the search criterion in topic, keywords or abstract fields. No limitation of time frame was used for the present study since we wanted to capture all the literature available on the topic. Only English language articles published in international peer reviewed journals were selected. The Scopus database search strategy generated 547 articles, while the Web of Science search strategy returned 284. The publication period runs from January 2001 (first paper published) to May 2016 (date when we closed our data collection procedure).

\section{Step 2: Data collection}

Bibliographic information about the selected papers (i.e. author/s, year, title, journal, keywords and summary) was downloaded from the above-mentioned databases into an Excel file. To minimize errors and ensure consistency, we crosschecked the retrieved descriptive information for each article, and we removed duplicates.

This initial scanning of articles was complemented by a more thorough reading process to determine the selected articled were really focused on TM. Accordingly, we deleted from our database those articles in which 'talent management' was used in a rather tangential manner (e.g., the use of the term in the title or keywords but without paying attention to the topic through the paper). An additional step was taken to ensure that the final selection of articles was consistent: we cross-checked our selection against a) the list of articles that have been used in previous literature reviews on TM, and b) against those articles cited in relevant recent publications. On completion of this task, we added 12 articles to our database. The final database for our analysis counted on 354 articles.

\section{Step 3: Data preparation}

Following Henriksen (2016) and Corley and Sabharwal (2010), we took co-authorship as the best proxy to the study of research collaboration. Thus, we manually deleted sole authored articles. Our final database used for network analysis comprised 225 co-authored 
papers (i.e., written by two or more authors), 494 authors, and 202 different keywords. It is worth noting that co-authored papers represent the $64 \%$ of all published articles on TM.

\section{Step 4: Data analysis and visualization}

We generated a series of co-occurrence matrices that provided a picture of the extent of collaboration among authors. Two authors were tied together (i.e. connected) if they had at least one publication in common. The strength of the tie (i.e. the sum of joint papers among them) indicates intensity. So as to better show the evolution of the network with time we decided to build one matrix per year starting in 2003 (first co-authored published paper in TM) through 2016, as well as a final matrix accounting for the entire period of analysis.

We implemented a subsequent three-stage approach in our analysis. First, we studied the evolution of the collaboration network by means of SNA, that is, how the network of collaborations has changed across time, both at structural and actor levels. Second, we performed a full period analysis (2003-2016) at the macro (density and cohesion), meso (fragmentation), and micro (centrality) levels that allowed us to identify the core of the collaboration network (i.e., the key players) and its structure (as we are about to see, they grouped up into two main communities). This allowed our analysis to focus on key players in order to attain a more in-depth view of individual authors' characteristics and attributes (gender, nationality and research interest) that help us understand the nature of their connection. The data required for this analysis was obtained from the publication itself, and from authors' information found on the Internet, particularly on institutional and personal web pages, Google scholar, LinkedIn, and Research Gate. The definition of the main research area was done, whenever possible, according to the author's own words (if they made that explicit in their affiliation web page, their $\mathrm{CV}$ or bios in social network profile). There was only one author for which was not possible to find trustworthy information. And third, we analysed the keywords appearing in the articles written by these key authors in order to identify the main topics studied and possible research trends. The analysis of keyword networks is useful to study the type of knowledge created in a domain (Choi et al., 2011). In fact, keywords and articles' titles are the best places to look for trends in a domain (Leydesdorff, 2006). We retrieved 203 different keywords from 66 articles. In order to make the analysis feasible and easily interpretable we decided to group keywords into general but relevant topics. We ended up with 79 topics. Thereafter, we created the topic co-occurrence matrices that provided us with a picture of the extent of relation within those topics (i.e., two topics were connected if they co-appear in an article). Finally, we performed a longitudinal analysis that leads us to see the evolution of topics within each community. 
We used specific software packages for Network Analysis: UCInet.6 for calculations and NetDraw for visualizations. An expert in SNA performed the analysis of the dataset, while all team members participated in the interpretation and discussion of the findings. By doing so, we tried to guarantee quality, objectivity and rigor.

\section{Findings}

\section{Overview of authorship data in TM research (2001-2016)}

Figure 1 illustrates the remarkable growth trajectory of TM scholarly research. A total of 354 articles were selected from 2001 to May of 2016, and the number of articles published increased each year, being the most prolific years 2013 and 2015 (51 articles each year). In line with recent literature reviews (Gallardo-Gallardo et al., 2015; McDonnell et al., 2017) the vast majority of papers (more than 90\%) were published post 2008, and specifically from 2010 onwards. Indeed, we can clearly appreciate the publication burst of scholarly interest in TM over the course of the last years.

-- Insert Figure 1--

The majority of papers (64\%) were co-authored. The first co-authored paper was published in 2003 by three authors. By June 2016, a total of 494 different authors had participated in at least one co-authored publication. Only $36 \%$ of the articles were soleauthored, and declining since 2012. We can definitely distinguish two periods: 2001-2009, and 2009-2016. In the first period, the number of sole-authored papers was greater than the number of co-authored papers, whereas in the second period there was a significant increase in multi-authored papers. This is consistent with findings in others disciplines (cf. Koseoglu, 2016), pointing to collaboration in research as a significant aspect in scientific development.

However, collaboration in TM research does not present a clear pattern. The collaboration index (i.e., total authors of co-authored articles/total of co-authored articles) ranged from 2 to 3 (mean $=2.6$ ). In fact, we found that two researchers is the most usual way of collaboration ( $31 \%$ of the articles), followed by a team of three authors $(21 \%)$. Four authors count for less than $10 \%$ of the papers. Only one paper (in 2012) is authored by a team of eight scientists, and a small number of papers (8) were authored by five authors in the period (2010-2015).

Evolution of co-authorship in TM research (2003-2016) 
Collaboration networks are evolving networks and the emphasis should be placed on their dynamics and growth. Not only new authors are constantly entering (and/or leaving) a field but internal links (collaborations) among existing network authors change too. Figure 2 shows how the network of collaborations has evolved through time, both at structural and actor levels. Each circle (or node) represents an author, and lines (or ties) connecting them represent co-authorship in publications. It is important to bear in mind that in SNA the visual representations do not follow a spatial logic. In fact, the nodes are placed randomly in the graphs following the optimization rule of avoidance (Hanneman and Riddle, 2005). Consequently, the relevant information is the existence (or not) of ties, their strength and structure, rather than the location of any node in the visual display. Identification labels of authors (names) have been removed from this figure in order to facilitate a complete overview of the structure of the network.

\section{-- Insert Figure 3--}

The network started as a rather atomized structure, and as more authors got to contribute and collaborate, the structure gained in complexity. As a result, some subsets became close-knit communities showing more frequent collaboration. In the period 20032007 the network was incipient, governed by atomization of dyads and, at most, by tryads of co-authors. In 2008 the first two Special Issues (SI) on TM were published and, for the first time, the structure showed subsets of actors of four members. One SI, published by the International Journal of Contemporary Hospitality Management (see D'Annunzio-Green et $a l, 2008)$, was related to the hospitality industry and was focused on retention, recruitment engagement and development issues in this sector. The Public Personnel Management journal published the other SI, in which we find two highly cited papers in TM literature: (a) Reilly (2008) that discussed the 'right course' for TM in the introduction of the SI; and (b) a conceptual paper from Garrow and Hirsh (2008) in which the authors posed, for the first time, TM issues of focus and fit. It is worth noting that the authors participating in such SI did not continue with their research in TM; so, it was like a very specific contribution from their side. Yet, the impact of SI in TM research is something worthy of consideration, not only in terms of 'peaks' of publications (Gallardo-Gallardo et al., 2015; McDonnell et al., 2017) but also in terms of actors involved (see Table 1 for a summary).

\section{-- Insert Table 1--}

The interactional trend in the network was maintained in 2009, with a limited minority of authors involved but two subsets of 4 authors collaborating. In 2010 a third SI was due, and another milestone was set: the number of co-authors more than doubled, and 
collaborations among subsets of 4 and 5 actors are rather more present. It was published by the Journal of World Business and focused on Global Talent Management (see Scullion et al., 2010). Contrarily to what happened in previous SI, the vast majority of authors participating in this one continued doing and publishing research on TM up until present day. In fact, two of the guest editors in 2010 are today among the most influential authors in the field (cf. Gallardo-Gallardo and Thunnissen, 2016, Gallardo-Gallardo et al., 2015). While in 2011 there is a slight recession (48 nodes in 2011 vs. 70 in 2010), 2012 seems to be the consolidation year for TM as a field with over 80 authors in the network. From 2013 onwards the structure can be considered as a relatively dense network compared to what have been reported for other fields, for example, strategic management (Koseoglu, 2016). The annual EIASM Workshops on TM starting 2012 seem to have contributed to that being the case. Indeed this annual workshop, promoted and chaired by Vaiman, Collings and Scullion, represents an important forum for the dissemination and exchange of research on TM, and the creation of collaboration networks. It is worthy to mention that three SI (Vaiman and Collings, 2013; Collings et al., 2015a; Scullion et al., 2016) are based on contributions to that workshop, and that the authors participating in them are well-known and active researchers in TM.

The first SI in the Human Resource Management Review (Dries, 2013) was based on a set of papers (partly overlapping) that aimed to offer conceptual foundations and theoretical frameworks for those researchers interested in TM, and that were presented as a symposium in the Academy of Management Conference in Boston (2012). The active role of Dries in this SI is unquestionable, and most of the authors participating in it have become active researchers in the field and regular co-authors. In 2014, the second SI in the Journal of World Business was published seeking to advance the understanding of the field by offering some conceptual papers together with some empirical research on the field (see Al Ariss et al., 2014a). It is probably the most international SI (i.e., 15 different nationalities involved from Europe, Asia, Australia and North-America). In brief, the special issues seem to have played a significant role in the growth and complexity of the network.

In order to better capture the properties of the TM network we are going to analyze the network quantitatively at two sub-levels: the network level (macro level) and the individual level (micro level). Density is an important characteristic of a network at a macro level since it captures the idea of cohesion. It is calculated by means of the ratio of the number of ties to the maximum possible number of ties. So, it ranges from 0 to a maximum of 1 , when all possible ties are present. In short, density shows the connection level among 
authors. Authors in a higher density network interact with others frequently. TM collaboration network's density generally shows a decreasing trend (see Figure 2), which does not imply a decreasing tendency of research collaboration. In fact, network density is inversely related to network size: the fewer number of actors participating in the relational structure, the highest the probabilities that each node is connected to all others. This is the case of the TM collaboration network, in which density values are higher in the 2003-2007 period when the size of the network was relatively smaller than in later years. So, decreasing density in TM collaboration network is because of the increasing network size.

At the micro level (node or actor level), the most widely statistic used to describe the co-authorship network is an author's degree centrality (Fischbach et al., 2011), which reflects the number of collaborators of researchers. In other words, degree centrality measures how many connections tie authors to their immediate neighbours in the network (i.e. it indicates the importance of a node). The most used measure for calculating this is the Freeman Degree, which is basically the arithmetic summa of the arches coming and going from each node. The average degree in our TM network is around 2, which means that each node has a mean of two co-authors. The average degree increases from 2007 to 2012. The value of the maximum degree is rather more variable with the highest peak in 2013 (a single actor had 8 connections). Table 2 shows top TM authors per year according to their Freeman Degree centrality. These authors are central due to the fact that have the maximum degree of centrality for that year and, because their degree is far from the rest of degrees of that year. It is interesting to see how during the first years, when there were few authors in the network, it was quite easy to be "a big fish". As the network grows, the maximum degrees increase together with the number of central actors.

\section{-- Insert Table 2--}

In brief, throughout the period we have witnessed how the TM network has reduced its density largely as a consequence of an increased number of authors publishing on the topic, while steadily increasing the average number of collaborations among authors (centrality degree).

\section{The social structure of TM research}

In this section we will depict the social structure of the scientific community of scholars working in the field of TM. Specifically, we are going to identify the most 
influential actors in terms of collaboration as to provide better insight into the structure and dynamics at the core level. In order to do so, we analysed the complete co-authorship network, which contains 494 nodes and 1152 ties. The density of the co-authorship TM network is $0.5 \%$. As mentioned before, low density is inherent in large networks as it is very sensitive to the size of the network: the more actors participating in the structure, the more difficult that the network presents high-density values.

Figure 3 illustrates the co-authorship TM network graphically. A circle represents an author (node). The size of the nodes has been set according to their centrality degree: the bigger the nodes, the higher the author's centrality. Likewise, the strength of ties indicates the intensity of the relationship: the thicker the line, the more papers a pair of authors wrote together. This figure shows the unevenness in the distribution of relations. The shape and size of the different components (collaboration units) is very heterogeneous: ranging from isolated dyads (i.e. pair of authors with a single collaboration between them), to more complex structures built around central actors or stable co-authorship links (such as those substructures located at the upper right area of the sociograph).

\section{-- Insert Figure 3 --}

In order to understand the importance of the nodes of the network we are going to analyse their centrality metrics, namely degree and betweenness. In fact, those authors with high degree or betweenness are usually considered 'key researchers' (see Fan et al., 2016). The results are shown in Table 3.

\section{-- Insert Table 3 --}

As regards author's Freeman degree centrality, two out of three authors have a degree of 1 or 2 , which means that throughout the period these authors have contributed probably with one publication in collaboration with one or two colleagues at maximum. So, most of the authors have few connections. However, it is interesting to note that $10 \%$ of the authors show a degree of 5 or above. They are shaded in a light purple colour in Figure 4. Particularly, the two most central authors (shaded in orange) score a degree above 20, followed by the third most active author showing a degree of 14 . This gap indicates the unevenness of degree distribution in the network.

\section{-- Insert Figure 4 --}

Since the Freeman centrality measure is highly dependent on the size of the neighbourhood, we have also used Betweenness as an additional indicator of centrality. Betweenness is based on the idea of intermediation, that is, the presence of a necessary actor between two others that are not directly connected. So, it captures author's importance and 
influence by determining how often a particular author is found on the shortest path between any pair of authors in the network (Racherla and $\mathrm{Hu}, 2010$ ). So, those that are in this shortest path would be highly central since they control the flow of information in the network. We found that $57 \%$ of the authors are acting as intermediaries in the network, which can be a result of: (1) a high level of local sub-structures, that is, collaborations around given isolated publications; and (2) some authors acting as bridges, largely those that have contributed to two papers with colleagues that are not related to each other in terms of co-authorship. In this respect, weak ties are interesting opportunities in terms of bridging; connecting different perspectives that otherwise would remain apart. It is interesting to note the difference in author ranks based on Freeman degree and Betweenness. Only few of the central authors appear in the top rank when their Betweenness metrics are taken into consideration. According to Racherla and $\mathrm{Hu}(2010)$ this result can be seen as the prominent authors of the field tend to work within relatively closely isolated subgroups. So, let now draw the attention to the meso level of analysis, which is associated with 'fragmentation' in SNA and seeks to detect to what extent there are critical or weak parts in the whole network structure.

Network fragmentation in TM co-authorship network is high as anticipated by a density score of $0.5 \%$. We have identified up to 193 differentiable components in the network. The size, the structure and the composition of the clusters vary widely (as mentioned before, most of them being dyads and tryads). We found the network to be characterized by a number of key core components and an abundance of authors that hold up the network bridging and linking different parts of the structure that would otherwise be disconnected. Those authors can be identified as cutpoints, just because they have other nodes depending on them. We found 30 nodes acting as cutpoints (see Figure 5). Without their participation the network structure would be rather more atomized, and thus the number of components would increase. In the next section we are going to dig deeper into the core components of the network.

\section{-- Insert Figure 5 --}

The core of the TM collaboration network

So as to identify the core components in the network structure we have considered three different aspects: a) the size of the components (number of authors participating in them), b) the relative presence of components of that size, and c) how many authors are participating at that level of component size and which percentage they represent. We found that 87 authors grouped into two big components compose the core of the collaboration 
network: A (with brown coloration and $\mathrm{N}=63$ ), and $\mathbf{B}$ (with light-grey coloration and $\mathrm{N}=24$ ). Paradoxically, the two components are not connected together, and their respective connectivity and structure patterns are slightly different, indicating two communities have been growing in parallel (see Figure 6).

\section{-- Insert Figure 6 --}

The two components differ, not only in size, but also in density and degree distribution. Looking at their density score we can conclude that component $\mathbf{A}$ is rather more fragmented and hierarchically organized than component B. While A has a density of $6.25 \%$, B's density is $14.5 \%$, meaning authors in Component $\mathbf{B}$ interact with each other more frequently, that is greater co-authorship and higher authors' ratio of collaboration. As regards centrality, it is worth noting that to a great extent the actors within these two components enjoy salient positions in previous indicators of degree, particularly, in intermediation. For component A three degree patterns can be differentiated: a first group with the vast majority of co-authors presenting a degree ranging from 1 to 4; a second group less populated ranging from 5 to 8; and a third group with the most relevant actors (degree of 9 and above). In contrast, component $\mathbf{B}$ only offers two groups of authors that are clearly defined: one includes degrees from 1 to 7 , and the other includes degrees from 11 to 17. As mentioned above, the degree is a measure of centrality based on the sum of ties for a given actor, so grouping actors by their score in terms of degree is to group them according their level of activity within the community. It is worth mentioning that taking $\mathrm{A}$ and $\mathrm{B}$ components together we find that $20 \%$ of the nodes (15 actors in total) should be considered as rather occasional contributors that can be attributed to the start of a collaboration relationship or basically a punctual collaboration. Those authors appear in the "core" structure because they are minor players well connected to the central ones. Table 4 shows the top five central authors of the core of TM collaboration network. It is interesting to note that researchers with a higher Betweenness centrality contribute more to the network's connectivity.

\section{-- Insert Table 4 --}

\section{Component A: The biggest and oldest one}

The component labelled as $\mathbf{A}$ (in brown colour) has 63 members (58\% men and 42\% women), largely belonging to Anglo-Saxon countries, namely the US (22.2\%), the UK $(22.2 \%)$ and Ireland (17.5\%). Figure 7 illustrates this predominance with green shades: dark green for Ireland, light green for the US and turquoise for the UK. The centre of the network is predominantly Irish, and the closer to the centre the more homogeneous relationships 
within countries. Note that the data on countries refer to the authors' affiliation (for whom they work), not to the authors' nationality. Moreover, men, with the exception of node $\mathbf{A}_{\mathbf{2}}$ that speaks for the most important woman position in this community, largely represent the centre of the network.

\section{-- Insert Figure 7 --}

Collaboration in this component started in 2005, although it is not until 2008 that coauthorship became constant within this component. The shape and characteristics of a "small world" can be observed here: cohesive clusters internally speaking, and less cohesive externally, that is few links with the network (Kronegger et al., 2012). There are two exceptions to this: the Finnish component (in red, right edge), and the German triangle (in dark purple, close to $\mathbf{A}_{\mathbf{1}}$ ) in which the authors are only connected among them and with node $\mathbf{A}_{1}$.

One of the main premises in SNA is that connections tend to be made among pairs of nodes that share similar characteristics (homophily). For Component A we found that $54 \%$ of the existing ties are connections between authors of the same gender, while only $7 \%$ are linking people working in the same country (this is also sensitive to the wide range of countries involved). In terms of research interests of the authors within this component, $45 \%$ of existing ties are made within the same research area (Figure 8). The network is mainly centred around experts working on International Human Research Management (bottle green) followed by Human Research Management (black). To a lesser extent, we find other research interests, such as: Corporate Social Responsibility, Cross-cultural management, Information Technology, Innovation, IT management, Knowledge Management, Leadership, Marketing, Methods, Organizational change, Organizational diversity management, Organizational Psychology, Strategic Human Resource management, Strategic management.

$$
\text { -- Insert Figure } 8 \text {-- }
$$

Note that around $11 \%(7 / 63)$ of the co-authors in this component are not academic researchers per se, but they come from consultancy and/or the private sector (in white). It is also worth mentioning that five of the actors in this component have been Guest Editors of journal Special Issues, and three of these actors have acted as chairpersons of the annual EIASM Workshop on TM since 2012.

\section{Component B: The latest and the feminized one}

Component $\mathbf{B}$ is rather smaller than Component $\mathbf{A}$ with 24 authors. Interestingly, the proportion of men and women in Component $\mathbf{B}$ is reversed: $58 \%$ are women and $42 \%$ are male. In terms of country diversity, the countries involved are basically The Netherlands 
(45.8 \%), Belgium (41.7\%) and Spain (12.5\%). Differently from Components A, the three most central authors in the network are women, labelled as $\mathbf{B}_{\mathbf{1}}, \mathbf{B}_{\mathbf{2}}$ and $\mathbf{B}_{\mathbf{3}}$.

Collaboration in Component $\mathbf{B}$ started in 2012, that is, seven years later than Component A. As mentioned above, Component $\mathbf{B}$ has higher cohesion and less country diversity than $\mathbf{A}$. As regards cohesion, it is clear that $\mathbf{B}_{\mathbf{1}}$ is the most central author (see Table 4). The second $\left(\mathbf{B}_{2}\right)$ and third $\left(\mathbf{B}_{3}\right)$ most important actors in the network are much less central to the network than $\mathbf{B}_{1}$. The collaboration pattern reveals that co-authorships are built and maintained, to a great extent, around $\mathbf{B}_{\mathbf{1}}$. Those collaborators close to the central node may act as intermediaries indirectly connecting the central nodes with those other more peripheral. In terms of Betweenness, $\mathbf{B}_{\mathbf{3}}$ is rather more central to the network than $\mathbf{B}_{2}$, as she is bridging two co-authorship substructures. In other words, $\mathbf{B}_{3}$ plays a crucial role in connecting different groups as a broker (Yin et al. 2006) or as a gatekeeper who controls information flows in the network (Abbasi et al. 2011).

The homophilic pattern by country is clear, with a predominantly Belgian nucleus around $\mathbf{B}_{1}$ (in light blue, upper left), a Belgian-Spanish collaboration (in light blue and orange), which is directly connected to the center and intermediating two Dutch subcommunities bridged by $\mathbf{B}_{3}$. Among all existing ties in Component $\mathbf{B}, 72 \%$ are made within the same country (see Figure 9).

\section{-- Insert Figure 9 --}

However, Component $\mathbf{B}$ is richer in terms of variety of research interests. Within this subcommunity there is a strong research tradition on Organizational Psychology $(50 \%$ of them) and Human Resource Management (16.7\%). Although, one could find some other areas of research such as: Academic careers, Economic evaluation of health systems, Family business, Work relations, Methods, Organization and dynamics of science, Strategic human resource management, and Strategic management. Indeed, three different patterns emerge (see, Figure 10). First, most actors tied to the main core $\left(\mathbf{B}_{1}\right)$ belong to the same research area: Organizational psychology (in purple). Second, the nodes acting as intermediaries come from the field of Human Resource Management $\left(\mathbf{B}_{2}\right.$ and $\mathbf{B}_{3}$, in orange). Third, the rest of contributors, which are less central to the network and represented by other colours, come from other research interests or fields of expertise (e.g., specific research methods).

It is worth noting that around $8.3 \%(2 / 24)$ of the co-authors in Component $\mathbf{B}$ come from consultancy and/or the private sector (in white). Finally, it is of relevance to mention that among all participants in Component B, only one has been Guest Editor of a journal Special Issue in 2013. 
-- Insert Figure 10 --

\section{Topics studied and research communities}

We performed a keyword analysis as they appear published in the articles from these key authors. Our purpose was to examine the relationship between topics covered and research communities, and to identify core research themes and how these change over time. We retrieved 203 different keywords from 66 different articles published between 2005 and 2016. In order to make the analysis feasible and understandable, we grouped keywords into 79 categories of topics, by merging synonyms or similar concepts.

We found that $80 \%$ of the topics are specific to either Component $\mathbf{A}$ or $\mathbf{B}$, whereas $20 \%$ of the topics were shared. We can infer that the two research communities on TM identified before have devoted their efforts to different research areas, probably due to the distinctive background and interests of the scholars that form them. This has also an effect on the structure since the two components are not linked together. Figure 11 shows the forty most central nodes in the network. It shows that either most keywords (nodes) belong to Component $\mathbf{A}$, or are shared by both components.

\section{-- Insert Figure 11 --}

It is interesting to note that "Talent management" was found to be the most central topic (keyword) in both communities of researchers. This finding could help to reinforce its use as the most sensible keyword in designing search strategies for literature reviews. "Human capital theory" and "HR architecture and contribution" were also identified as central topics in both components, which can somehow explain that Resource Based View is the most used theoretical framework in TM research (Gallardo-Gallardo et al., 2015). "High potentials", "Talent concept", “Qualitative research" are other relevant topics shared by both communities.

Figure 12 presents the key topics within Component A, which can clearly be linked to the International Human Resource Management (IHRM) field, that is, one of the main areas of research among these authors. Some of the key themes are: "MNEs", "IHRM", "Local adaptation and knowledge", "Diaspora", "Globalization", "Expatriation" and "Knowledge management". Being Component A both the largest and the oldest scholars' community it could help in explaining: (i) previous criticism about the focus of TM literature on multinational and private organizations (Collings et al., 2011b, Powell et al., 2013); (ii) why IHRM is the second most prevalent theoretical framework in TM literature (GallardoGallardo et al., 2015); and (iii) why GTM is one of the main topics studied (GallardoGallardo and Thunnissen, 2016). 
-- Insert Figure 12 --

Figure 13 depicts the most central topics in Component B. Specifically from this community we find a set of keywords including: "Literature review", "Theoretical propositions", "Bibliometric analysis", and "Phenomenon-driven research". Further, we found topics related to theoretical approaches, one bold explanation for this being that within this component we find most of the recent attempts to theoretically advance and differentiate the field.

\section{-- Insert Figure 13 --}

Table 5 shows how topics evolve through time for both components. It provides an overview of central topics through time, "Talent Management" being present in both components. There seems to be a greater dispersion (array) of topics in Component A, probably as a result of a higher number of researchers in the network. Further, Component A shows a clear interest in "MNEs", "Global Talent Management" and all other factors related to these (e.g. "Diaspora", "Local adaptation", "Careers"). Differently, Component B shows a strong emphasis on the conceptualization of talent ("Talent concept", "Nature-nurture", "High potentials") and in "Careers".

\section{-- Insert Table 5 --}

\section{Discussion}

This paper is the first to disclose the dynamics in TM research through a detailed analysis of its evolving collaboration networks, identifying key players and major topics covered. Our findings provide evidence on both the structure and evolution of collaborations among authors in the field. We used co-authorship as the proxy to collaboration and by means of SNA we offered an "aerial" view of the structure and nature of TM research communities. We understand the study findings are useful in many ways we convey below.

First, we are in a position to support the fact that Talent Management research has evolved from its earliest stage of development to a rather more mature stage. This is shown, for example, by the increased ratio of research collaboration, which is in line with findings in numerous social science research fields (Henriksen, 2016). We have also witnessed the formation of research teams, which can be seen as evidence of its evolution into a more mature stage of development (Gallardo-Gallardo et al., 2015). Further, our longitudinal analysis has facilitated the identification of two main factors that could explain growth and peaks in the collaboration trends, namely, published journal special issues and EIASM workshops on TM. Indeed, both EIASM workshops and the journal special issues have revealed as key strategic policies for network creation and development to date. In the years 
to come if such policies are bound to produce sizable returns it would largely depend on how we could best identify the knowledge areas around which conferences, workshops and special journal issues would be organized. We consider crucial to launch specific calls as opposed to generic calls to boost advances in the field and consolidate certain streams, since the field is no more in an embryonic stage (see Gallardo-Gallardo et al., 2015). For instance, calls that lead to study underexplored hot strategic topics (e.g., the impact of cultural factors in the operationalization of TM, the role of team dynamics within TM, the impacts of new forms of digital work) or regions (e.g., Africa, South European region, The Middle East, the Pacific Region, South- and Central America). Also it would be interesting to find specific calls that encourage creativity in approaching TM from 'alternative' angles so as the TM field could benefit from enlarging the theoretical playing field. Moreover, and due to recent critiques on the way TM is investigated (see Thunnissen and Gallardo-Gallardo, 2017) those key players in these strategic policies must actively encourage and demand high standards of quality and rigour.

Second, the results demonstrate the rapid evolution of the TM co-authorship network despite it cannot be considered a very cohesive community (i.e., most of the authors have few connections), and the groups of reference are many and usually not connected to each other. Although this could be seen as a characteristic of an evolving field, it also poses many challenges to its potential development. Future strategies may want to consider strengthening not only productive teams but also those who contribute significantly to the connectivity of the network (Fan et al. 2016), particularly fostering collaboration between Components A and B. To date, these components have been growing in parallel for some years. Our findings in this sense are in line with McDonnell and Collings (2015) claim of the failure to effectively integrate insights from US and European literature streams in TM. In addition, intra-country collaboration has shown to be frequent in the network for which betting on proximity in the formation of research teams seems to be a sound strategy too.

Third, from the analysis of topics we could argue that the two communities studied TM from different angles. In the largest and oldest one (Component A, Anglo-Saxon), "Global Talent Management" is the main topic of study, whereas component B (European non Anglo-Saxon) is focused on the advancement of the field ("Literature review", -Theoretical frameworks"). Further qualitative analysis on the characteristics of these networks could assist in the design of actions to promote cross-disciplinary research, and thereafter a more connected network. 
This study is subject to some limitations we would like to disclose. First, the data set used for this study cannot be considered to be optimal, since we agreed to include articles written in English and published in peer-reviewed journals. We disregarded other interesting outlets (e.g., books, conference proceedings, reports, working papers) that could be significant to show the evolution of collaboration networks in growing fields. However, we do not consider this to void the results. Second, we did not include all papers published in 2016, which could make this year incomparable with other years. That is why we are cautious with the conclusions extracted from that particular year. Third, we used co-authorship as a proxy to collaboration. This has been criticized on two grounds by some authors (Henriksen, 2016; Zupic and Cater, 2015): co-authors are not always collaborators, and informal collaborations are being neglected (i.e., sharing ideas, discussions or pre-reviews of the paper). Despite this, co-authorship is still considered the best possible proxy to collaboration (Corley and Sabharwal, 2010), and it embodies several advantages too, such as being invariable, practical and inexpensive (see Perianes-Rodríguez et al., 2010). Finally, our keyword analysis, although insightful, should be seen as an introductory work for many reasons. We are only considering keywords used by those key authors included in our study, and therefore ignoring other keywords used by other authors. We believe, however, that our analysis, although limited to a subset of scholars, could be seen as relevant since we are focusing on those that have a great impact in the TM field. Moreover, we are just focusing on author-supplied keywords, which means we are relying on their sound judgement in selecting keywords. In addition, a profound analysis of the intellectual roots of each collaboration network should be done by means of citation and co-citation analysis, or better, performing a co-word analysis of the papers published. Finally, the author supplied keyword co-occurrence network analysis in this paper could be complemented with a title keyword co-occurrence network analysis to appraise emerging and fading themes (see Leydesdorff, 2006).

From our analysis we can identify a number of avenues for future research. One possible fruitful line of research would be to perform a co-citation analysis. This would enhance our understanding of the theoretical origins, intellectual structure and outlook of TM research, as well as the disclosure of 'invisible colleges' (see Batistic and Kase, 2015, Cerne et al., 2016, Vogel, 2012). Indeed, co-citation analysis would allow for a better appraisal of knowledge flow among academic papers and specialties (i.e., the cross-pollination of ideas across knowledge domains) (Ciotti et al., 2016, Nerur et al., 2015). Further, this analysis would help in estimating the impact of how authors' embeddedness in research communities affects their research in terms of impact (see Collet et al., 2014, Fischbach et al., 2011) 
Another possible line of future research is to examine co-authorship networks by means of an improved mixed-method approach (i.e., combining qualitative and quantitative methods to enrich the explanation of underlying processes and their meaning to the actors involved). This would avoid an overemphasis on the structural dimension of social networks at the expense of the relational contents (see Kase et al., 2013), and assist in finding answers to questions regarding processes and factors that explain co-authorship (Velden and Lagoze, 2013; Velden et al. 2010; Fry and Talja, 2007).

In addition, a deeper study into how international collaboration shapes TM and how national research communities are internally and internationally interlinked (see Glänzel and de Lange, 2002) would be of high added value to the understanding of TM dynamics in the future, and to the design of adequate strategies to expand the traditional TM areas of interest to rather underexplored domains. Likewise, qualitative studies that allow to explain how new topics and perspectives are adopted would not only affect the development of the scientific debate, but the scientific community that forms around them.

Acknowledgements: We would like to express our sincere gratitude to the Guest Editors of this special issue and the two anonymous reviewers for their helpful observations and suggestions on previous versions of this manuscript.

\section{References}

Al Ariss, A., Cascio, W.F. and Paauwe, P. (Ed.) (2014a), "Talent management: current theories and future research directions" [Special Issue], Journal of World Business, Vol. 49 No. 2.

Al Ariss, A., Cascio, W.F. and Paauwe, P. (2014b), "Talent management: current theories and future research directions" [Special Issue], Journal of World Business, Vol. 49 No. 2, pp. 173-179.

Batistic, S. and Kase, R. (2015), "The organizational socialization field fragmentation: a bibliometric review", Scientometrics, Vol. 104 No.1, pp. 121-146.

Cappelli, P. (2008), “Talent Management for the Twenty-First Century”, Harvard Business Review, Vol. 86 No.3, pp. 74-81. 
Cappelli, P. (2010), "The rise and decline of executive development", Industrial and Corporate Change, Vol. 19 No 2, pp. 509-548.

Cappelli, P. and Keller, J. (2014), "Talent Management: Conceptual Approaches and Practical Challenges", Annual Review of Organizational Psychology and Organizational Behaviour, Vol. 1 No 1,pp. 305-331.

Cascio, W. F. and Boudreau, J. W. (2016), "The search for global competence: From international HR to talent management", Journal of World Business, Vol. 51 No 1, pp. 103114.

Cerne, M., Kase, R. and Skerlavaj, M. (2016), "Non-technological innovation research: evaluating the intellectual structure and prospects of an emerging field", Scandinavian Journal of Management, Vol. 32 No.2, pp. 69-85.

Chambers, E.G., Foulon, M., Handfield-Jones, H., Hankin, S. and Michaels, E.G. (1998), "The war for talent", The McKinsey Quarterly, Vol. 3, pp. 1-8.

Choi, J., Yi, S., and Lee, K. C. (2011), “Analysis of keyword networks in MIS research and implications for predicting knowledge evolution", Information \& Management, Vol. 48 No. 8, pp. 371-381

Ciotti, V., Bonaventura, M., Nicosia, V., Panzarasa, P. and Latora, V. (2016), "Homophily and missing links in citation networks”, EPJ Data Science, Vol. 5 No 7, pp. 2-14.

Collet, F., Robertson, D. A. and Lup, D. (2014), "When does brokerage matter? Citation impact of research teams in an emerging academic field", Strategic Organization, Vol. 12 No 3, pp. 157-179.

Collings, D. G. (2015), “The contribution of Talent Mangement to organizational success", in Passmore, J., Kraiger, K, and Santos, N. (Eds.), The Wiley Blackwell Handbook of the Psychology of Training, Development and Feedback, London, Wiley Blackwell, pp. 247-260. 
Collings, D. G., Scullion, H., and Vaiman, V. (Eds.) (2011a), "European perspectives on talent management" [Special Issue], European Journal of International Management, Vol. 5 No 5 .

Collings, D. G., Scullion, H., and Vaiman, V. (2011b), "European perspectives on talent management" [Special Issue], European Journal of International Management, Vol. 5 No 5, pp. $453-462$.

Collings, D. G., Scullion, H. and Vaiman, V. (Eds.) (2015a), “Talent management: Progress and prospects" [Special Issue], Human Resource Management Review, Vol. 25 No 3.

Collings, D. G., Scullion, H. and Vaiman, V. (2015b), "Talent management: Progress and prospects" [Special Issue], Human Resource Management Review, Vol. 25 No 3, pp. 233235.

Corley, E. A., and Sabharwal, M. (2010), "Scholarly collaboration and productivity patterns in public administration: Analysing recent trends", Public administration, Vol. 88 No 3, pp. 627-648.

D'Annunzio-Green, N., Maxwell, G. and Watson, S. (Eds.) (2008), "What are the contemporary human resource issues for talent management in hospitality and tourism?" [Special Issue], International Journal of Contemporary Hospitality Management, Vol 20 No 7.

Dries, N. (Ed.) (2013), "Talent management, from phenomenon to theory: Introduction to the Special Issue” [Special Issue], Human Resource Management Review, Vol. 23 No 4.

Fan, W., Li, G. and Law, R. (2016), “Temporal analysis of tourism research collaboration network", Journal of Hospitality and Tourism Research, Vol. 41 No 6, pp. 643-672.

Fischbach, K., Putzke, J. and Schoder, D. (2011), "Co-authorship networks in electronic markets research", Electronic Markets, Vol. 21 No 1, pp. 19-40. 
Fry, J. and Talja, S. (2007), "The intellectual and social organization of academic fields and the shaping of digital resources", Journal of Information Science, Vol. 33 No 2, pp. 115-133.

Gallardo-Gallardo, E., Dries, N. and González-Cruz, T. (2013), "What is the meaning of 'talent' in the world of work?" [Special Issue], Human Resource Management Review, Vol. 23 No 4, pp. 290-300.

Gallardo-Gallardo, E., Nijs, S., Dries, N. and Gallo, P. (2015), “Towards an understanding of talent management as a phenomenon-driven field using bibliometric and content analysis" [Special Issue], Human Resource Management Review, Vol. 25 No 3, pp. 264-279.

Gallardo-Gallardo, E. and Thunnissen, M. (2016), "Standing on the shoulders of giants? A review of empirical talent management research" [Special Issue],, Employee Relations, Vol. 38 No. 1, pp. 31-56.

Garrow, V. and Hirsh, W. (2008), "Talent management: Issues of focus and fit" [Special Issue], Public Personnel Management, Vol. 37 No 4, pp. 389-402.

Gherardini, A. and Nucciotti, A. (2017), "Yesterday's giants and invisible colleges of today. A study on the 'knowledge transfer' scientific domain”, Scientometrics, Vol. 112 No.1, pp. $255-271$.

Glänzel, W. and de Lange, C. (2002), “A distributional approach to multinationality measures of international scientific collaboration”, Scientometrics, Vol. 54 No. 1, pp. 75-89.

Hanneman, R.A. and Riddle, M. (2005), Introduction to social network methods, University of California: Riverside (CA). Available at http://faculty.ucr.edu/ hanneman/.

Henriksen, D. (2016), "The rise in co-authorship in the social sciences", Scientometrics, Vol. 107 No.2, pp. 455-476. 
Kase, R., King, Z. and Minbaeva, D. (Eds.) (2013), "Using social network research in HRM: Scratching the surface of a fundamental basis of HRM" [Special Issue], Human Resource Management, Vol. 52 No 4, pp. 473-483.

Koseoglu, M. A. (2016), "Growth and structure of authorship and co-authorship network in strategic management realm: Evidence from the Strategic Management Journal”, Business Research Quarterly, Vol. 19 No.3,pp. 153-170.

Leydesdorff, L. (2006), The knowledge-based economy: Modeled, measured, simulated. Universal Publishers, Boca Raton (FL).

Lewis, R. E. and Heckman, R. J. (2006), “Talent management: A critical review”, Human Resource Management Review, Vol. 16 No 2, pp. 139-154.

Leydesdorff, L. (2006). The knowledge-based economy: Modeled, measured, simulated. Boca Raton, FL: Universal Publishers.

Michaels, E., Handfield-Jones, H., and Alexrod, B. (2001), The war for talent. Harvard Business Press, Boston (MA).

McDonnell, A. and Collings, D. G. (2015), "Towards a balanced understanding of talent management: Integrating US and European perspectives", Paper presented within the Academy of Management symposium “Talent Management: Towards Balance in Theory and Research”.

McDonnell, A., Collings, D. G., Mellahi, K. and Schuler, R. (2017), “Talent management: a systematic review and future prospects", European Journal of International Management, Vol.1 No 1, pp. 86-128.

Nerur, S., Rasheed, A.A. and Pandey, A. (2015), "Citation foot-prints on the sands of time: an analysis of idea migrations in strategic management", Strategic Management Journal, Vol. 37 No. 6, pp. 1065-1084. 
Perianes-Rodríguez, A., Olmeda-Gómez, C. and Moya-Anegón, F. (2010), "Detecting, identifying and visualizing research groups in co-authorship networks", Scientometrics, Vol. 82 No.2, pp. 307-319.

Powell, M., Duberley, J., Exworthy, M., Macfarlane, F. and Moss, P. (2013), "Has the British National Health Service (NHS) got talent? A process evaluation of the NHS talent management strategy?", Policy Studies, Vol. 34 No 3, pp. 291-309.

Racherla, P. and $\mathrm{Hu}, \mathrm{C}$. (2010), "A social network perspective of tourism research collaborations", Annals of Tourism Research, Vol. 37 No 4, 1012-1034.

Reilly, P. (Ed.) (2008), "Identifying the right course for talent management" [Special Issue], Public Personnel Management, Vol. 37 No 4.

Sarafoglou, N. and Paelinck, J. H. P. (2008), "On diffusion of ideas in the academic world: The case of spatial econometrics", The Annals of Regional Science, Vol. 42 No 2, pp. 487500 .

Scullion, H., Collings, D. G. and Caligiuri, P. (Eds.) (2010), "Global talent management" [Special Issue], Journal of World Business, Vol 45 No 2.

Scullion, H., Vaiman, V. and Collings, D. G. (Eds.) (2016), "Strategic talent management" [Special Issue], Employee Relations, Vol 38 No 1.

Swailes, S. (2016), "The cultural evolution of talent management: A memetic analysis", Human Resource Development Review, Vol. 15 No 3, pp. 340-358.

Thunnissen, M., and Gallardo-Gallardo, E. (2017), "Quality and rigor in empirical TM research: opportunities and challenges" paper presented at the $6^{\text {th }}$ EIASM Workshop on TM, 2-3 October, Barcelona, Spain. 
Thunnissen, M., Boselie, P. and Fruytier, B. (2013), "A review of talent management: 'infancy or adolescence?” [Special Issue], The International Journal of Human Resource Management, Vol. 24 No. 9, pp. 1744-1761.

Upham, S. P. and Small, H. (2010), "Emerging research fronts in science and technology: Patterns of new knowledge development", Scientometrics, Vol. 83 No 1, pp. 15-38.

Vaiman, V. and Collings, D. G. (Eds.) (2013), "Talent management: advancing the field" [Special Issue], International Journal of Human Resource Management, Vol. 24 No 9.

Velden, T., and Lagoze, C. (2013), "The Extraction of Community Structures from Publication Networks to Support Ethnographic Observations of Field Differences in Scientific Communication", Journal of the American Society for Information Science and Technology, Vol. 64 No 12, pp. 2405-2427.

Velden, T., Haque, A. and Lagoze, C. (2010), “A new approach to analyzing patterns of collaboration in co-authorship networks: mesoscopic analysis and interpretation", Scientometrics, Vol. 85 No.1, pp. 219-242.

Vogel, R. (2012), “The visible colleges of management and organization studies: A bibliometric analysis of academic journals", Organization Studies, Vol. 33 No 8, pp. 10151043.

Wasserman, S., \& Faust, K. (1994). Social network analysis: Methods and applications, Cambridge University Press, New York.

Yan, L., Guo, M. and Li, Y. (2012), “An empirical research on international competitiveness of China's trade in service", International Journal of Information Processing and Management, Vol.3 No 2, pp. 44-55.

Zhang, K., Wang, Q., Liang, Q-M. and Chen, H. (2016), “A bibliometric analysis of research on carbon tax from 1989 to 2014”, Renewable and Sustainable Energy Reviews, Vol. 58, pp. 297-310. 
Zuccala, A. (2006), "Modeling the invisible college", Journal of the American Society of Information Science and Technology, Vol. 57 No 2, pp. 152-168.

Zupic, I. and Cater, T. (2015), "Bibliometric methods in management and organization", Organizational Research Methods, Vol. 18 No. 3, pp. 429-472. 
Fig. 1 Publications per year and general data on authorship

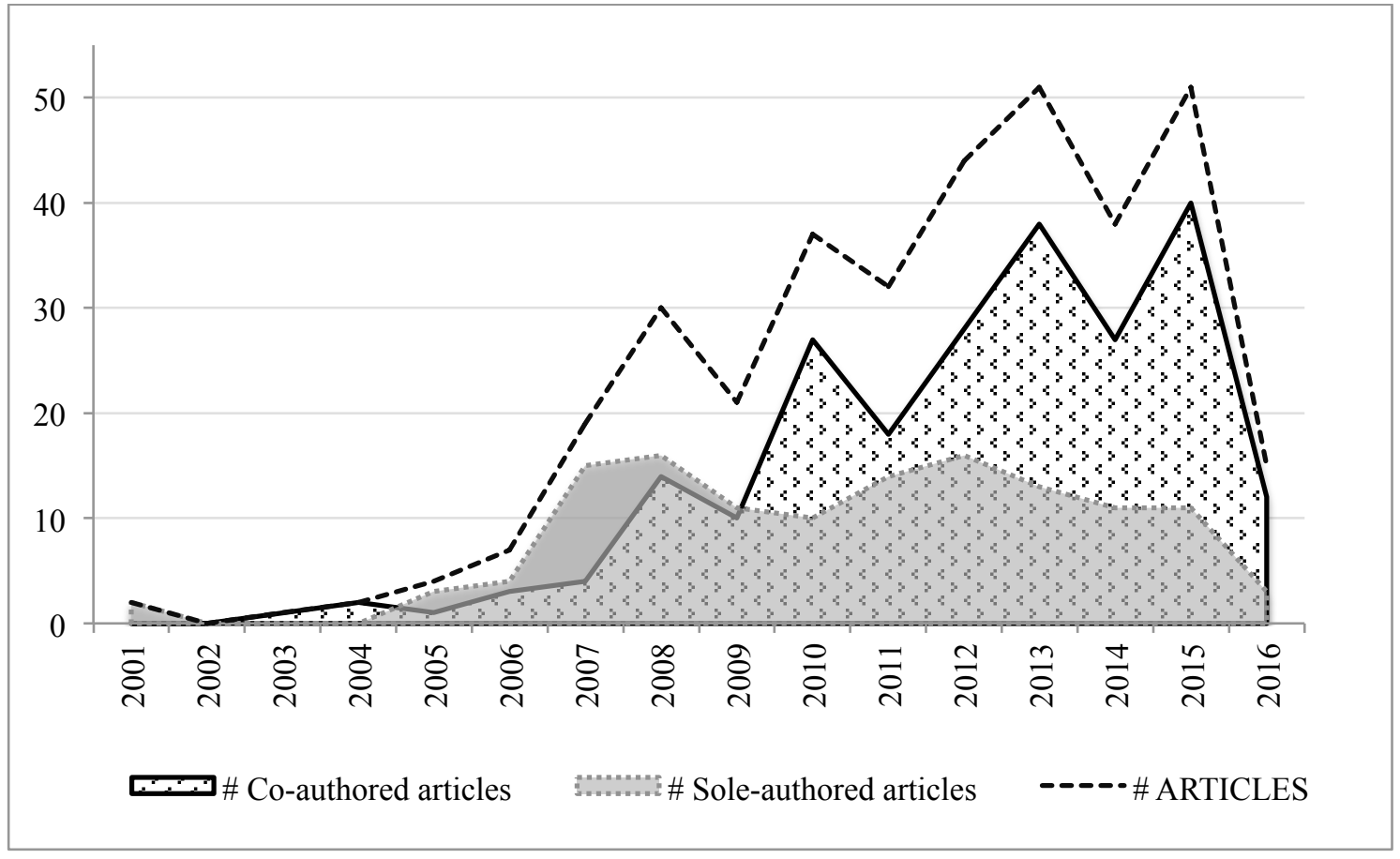

Note: Retrieved data to the end of May of 2016 
Fig. 2 Evolution of the collaboration network (by year)

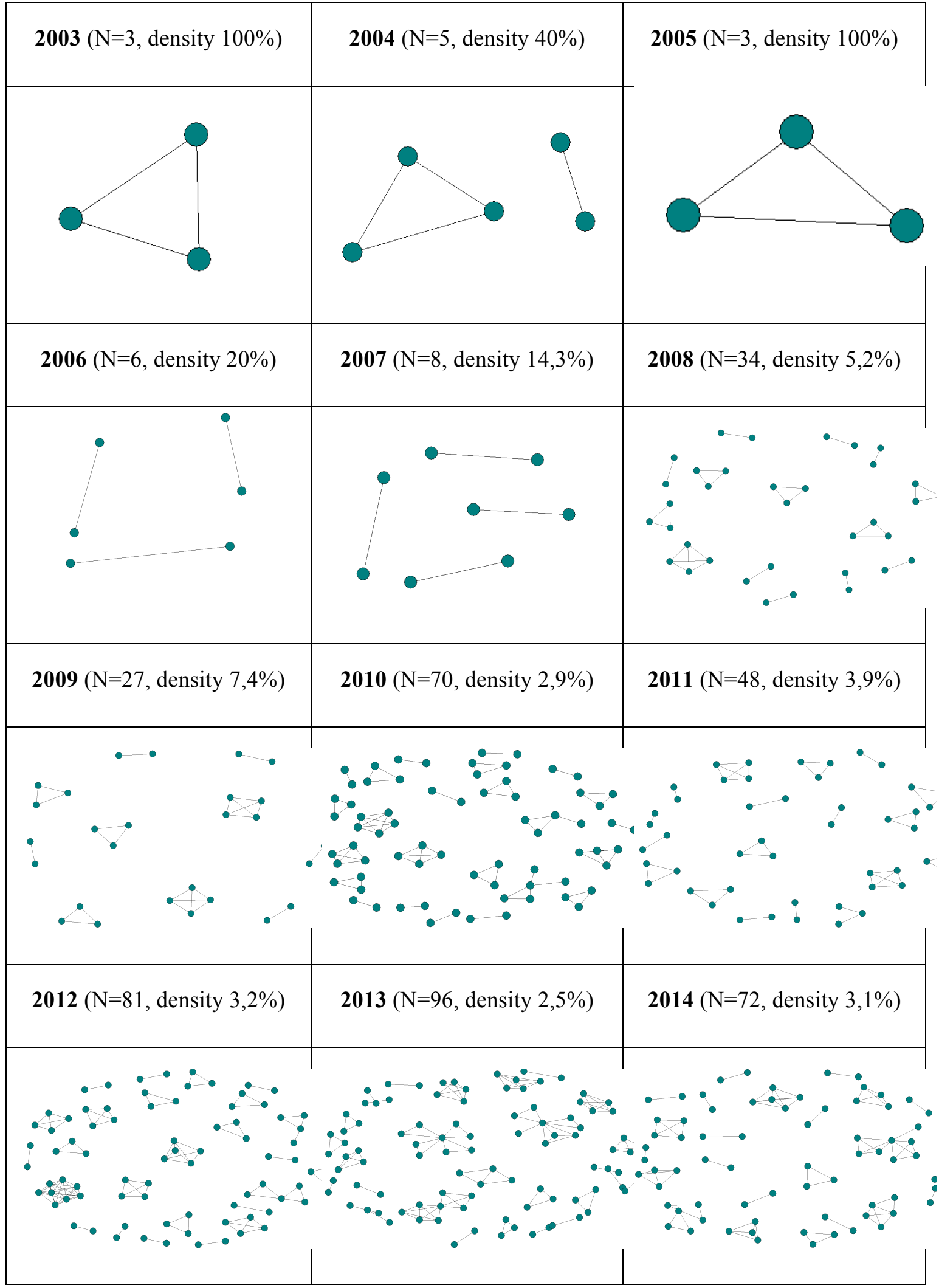


Fig. 2 Evolution of the collaboration network (by year) (cont.)

$2015(\mathrm{~N}=107$, density $2,1 \%) \quad 2016(\mathrm{~N}=34$, density $6,4 \%)$

Note: $\mathrm{N}=$ number of authors; Density = proportion of the existing ties among all the possible ties. It ranges from 0 to 1 and it is expressed as a percentage. 
Table 1 Special Issues and Guest Editors in TM

\begin{tabular}{|c|c|c|}
\hline Year & Journal & Guest editors" \\
\hline 2008 & $\begin{array}{l}\text { International Journal of } \\
\text { Contemporary Hospitality } \\
\text { Management }\end{array}$ & $\begin{array}{l}\text { D'Annunzio-Green, N. } \\
\text { Maxwell, G. } \\
\text { Watson, S. }\end{array}$ \\
\hline 2008 & $\begin{array}{l}\text { Public Personnel } \\
\text { Management }\end{array}$ & Reilly, P. \\
\hline 2010 & Journal of World Business & $\begin{array}{l}\text { Scullion, H. } \\
\text { Collings, D. G. } \\
\text { Caligiuri, P. } \\
\end{array}$ \\
\hline 2011 & $\begin{array}{l}\text { European Journal of } \\
\text { International Management }\end{array}$ & $\begin{array}{l}\text { Collings, D. G. } \\
\text { Scullion, H. } \\
\text { Vaiman, V. }\end{array}$ \\
\hline 2012 & $\begin{array}{l}\text { Asia Pacific Journal of } \\
\text { Human Resources }\end{array}$ & $\begin{array}{l}\text { McDonnell, A. } \\
\text { Collings, D. G. } \\
\text { Burgess, J. }\end{array}$ \\
\hline 2012 & $\begin{array}{l}\text { European Journal of } \\
\text { Training and Development }\end{array}$ & $\begin{array}{l}\text { Garavan, T. N. } \\
\text { Carbery, R. } \\
\text { Rock, A. } \\
\end{array}$ \\
\hline 2013 & $\begin{array}{l}\text { Human Resource } \\
\text { Management Review }\end{array}$ & Dries, $\mathbf{N}$. \\
\hline 2013 & $\begin{array}{l}\text { International Journal of } \\
\text { Human Resource } \\
\text { Management }\end{array}$ & $\begin{array}{l}\text { Vaiman, V. } \\
\text { Collings, D. G. }\end{array}$ \\
\hline 2014 & Journal of World Business & $\begin{array}{l}\text { Al Ariss, A. } \\
\text { Cascio, W. F. } \\
\text { Paauwe, J. }\end{array}$ \\
\hline 2015 & $\begin{array}{l}\text { Human Resource } \\
\text { Management Review }\end{array}$ & $\begin{array}{l}\text { Collings, D. G. } \\
\text { Scullion, H. } \\
\text { Vaiman, V. }\end{array}$ \\
\hline 2016 & Employee Relations & $\begin{array}{l}\text { Scullion, H. } \\
\text { Vaiman, V. } \\
\text { Collings, D. G. }\end{array}$ \\
\hline
\end{tabular}

Notes: ${ }^{*}$ Those authors marked in bold belong to the core of authors 
Table 2 Top central authors in TM network per year

\begin{tabular}{|c|c|c|c|c|c|c|c|c|c|c|c|}
\hline Year & Most central nodes & Degree & Year & Most central nodes & Degree & Year & Most central nodes & Degree $^{*}$ & Year & Most central nodes & Degree \\
\hline 2003 & $\begin{array}{l}\text { Hazucha, J. F. } \\
\text { Sloan, E. B. } \\
\text { Van Katwyk, P. T. }\end{array}$ & 2 & 2007 & $\begin{array}{l}\text { Conger, J. A. } \\
\text { Gakovic, A. } \\
\text { Lacey, M.Y. } \\
\text { Millen, J. } \\
\text { Ready, D. A. } \\
\text { Tompkins, T.C. } \\
\text { Wintzéus, R. } \\
\text { Yardley, K. }\end{array}$ & 1 & 2011 & $\begin{array}{l}\text { Carland, J. C. } \\
\text { Carland, J. W. } \\
\text { Doh, J. P. } \\
\text { Ensley, M. D. } \\
\text { Ensley, R. L. } \\
\text { Smith, R. R. } \\
\text { Stumpf, S. A. } \\
\text { Tymon Jr., W. G. }\end{array}$ & 3 & 2015 & $\begin{array}{l}\text { Dries, N. (6) } \\
\text { Schuler, R. S. (5) }\end{array}$ & 5,6 \\
\hline 2004 & $\begin{array}{l}\text { Davis, P. } \\
\text { Naughton, J. } \\
\text { Rothwell, W. J. }\end{array}$ & 2 & 2008 & $\begin{array}{l}\text { Chuai, X. } \\
\text { Iles, P. } \\
\text { Preece, D. } \\
\text { Stiles, P. }\end{array}$ & 3 & 2012 & $\begin{array}{l}\text { Björkman, I. } \\
\text { Farndale, E. } \\
\text { Morris, S. S. } \\
\text { Paauwe, J. } \\
\text { Stahl, G. K. } \\
\text { Stiles, P. } \\
\text { Trevor, J. } \\
\text { Wright, P. M. }\end{array}$ & 7 & 2016 & $\begin{array}{l}\text { Gunnigle, P. } \\
\text { Harvey, M. } \\
\text { Hawks, M. } \\
\text { Heijne-Penning, } \\
\text { M. } \\
\text { Kiessling, T. } \\
\text { Lamare, R. } \\
\text { Lavelle, J. } \\
\text { LeMire, S. } \\
\text { Maley, J. } \\
\text { McDonnell, A. } \\
\text { Moeller, M. } \\
\text { Mowdood, A. } \\
\text { Paans, W. } \\
\text { Rutledge, L. } \\
\text { van Heugten, P. } \\
\text { Wolfensberger, M. }\end{array}$ & 3 \\
\hline 2005 & $\begin{array}{l}\text { Davis, P. } \\
\text { Lachenauer, R. } \\
\text { Naughton, J. } \\
\text { Rothwell, W. J. } \\
\text { Stalk, G. }\end{array}$ & 2 & 2009 & $\begin{array}{l}\text { Bracco, A. } \\
\text { Clarke, R. L. } \\
\text { Fetters, R. } \\
\text { Glinow, M. V. } \\
\text { Meyskens, M. } \\
\text { Riester, D. } \\
\text { Robinson, C. } \\
\text { Werther, W. B. }\end{array}$ & 3 & 2013 & $\begin{array}{l}\text { Dries, N. (8) } \\
\text { Scullion, H. (8) } \\
\text { Vance, C. M. (7) }\end{array}$ & 7,8 & & & \\
\hline 2006 & $\begin{array}{l}\text { Burkhardt, G. } \\
\text { Gerard, D. } \\
\text { Hadida, A. L. } \\
\text { Heckman, R. J. } \\
\text { Lewis, R. E. } \\
\text { Seifert, M. }\end{array}$ & 1 & 2010 & $\begin{array}{l}\text { Hor, F. C. } \\
\text { Huang, L.-C. } \\
\text { Lee, E. S. } \\
\text { Lee, Y.-H. } \\
\text { Scullion, H. } \\
\text { Shih, H.-S. }\end{array}$ & 4 & 2014 & $\begin{array}{l}\text { Barkhuizen, N. (5) } \\
\text { Dries, N. (7) } \\
\text { Schutte, N. (5) }\end{array}$ & 5,7 & & & \\
\hline
\end{tabular}

Note: *Freeman Degree centrality measure 
Fig. 3 Co-authorship network in TM research (period 2003-2016)

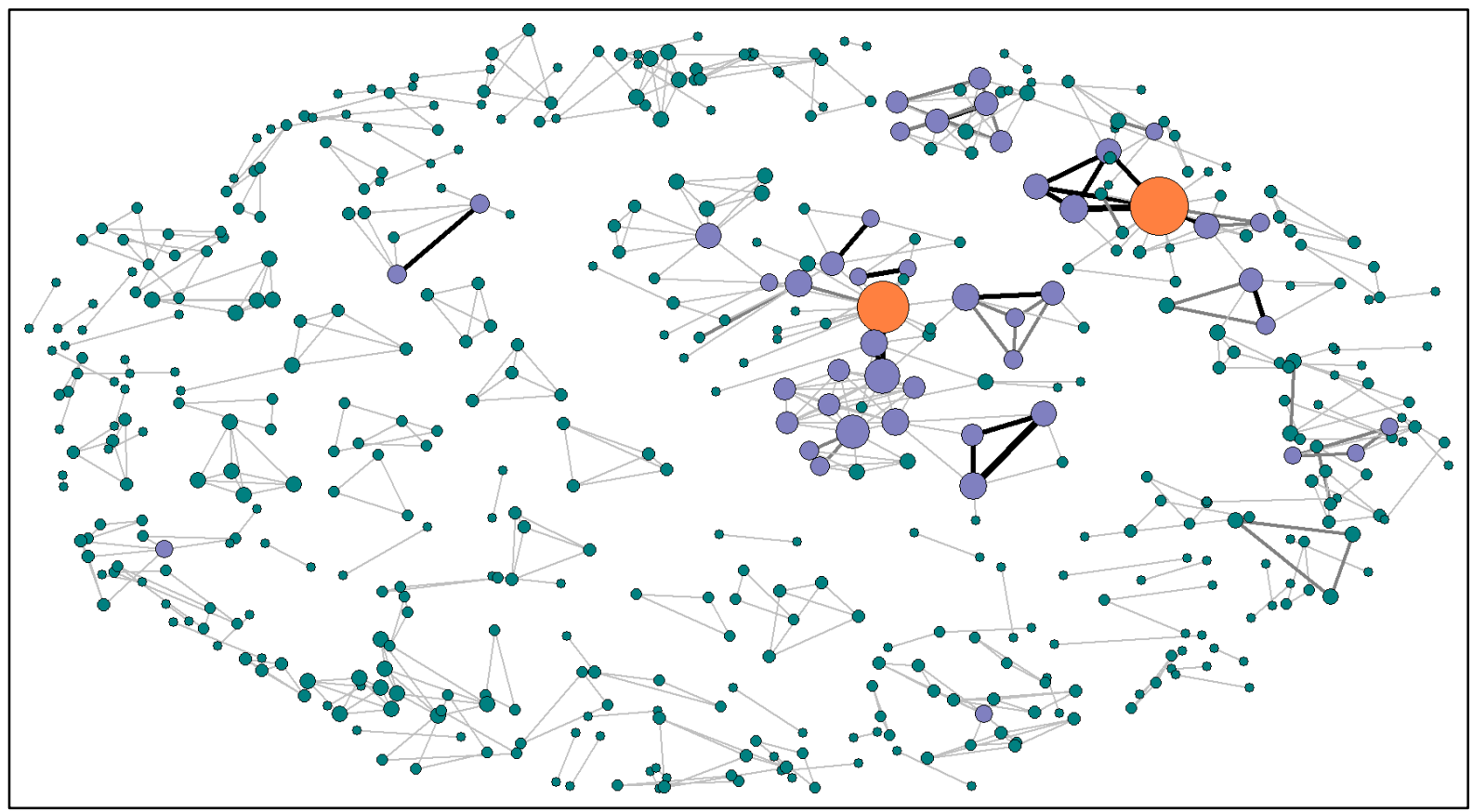


Fig. 12 Subset of most central topics within component A (N=63)

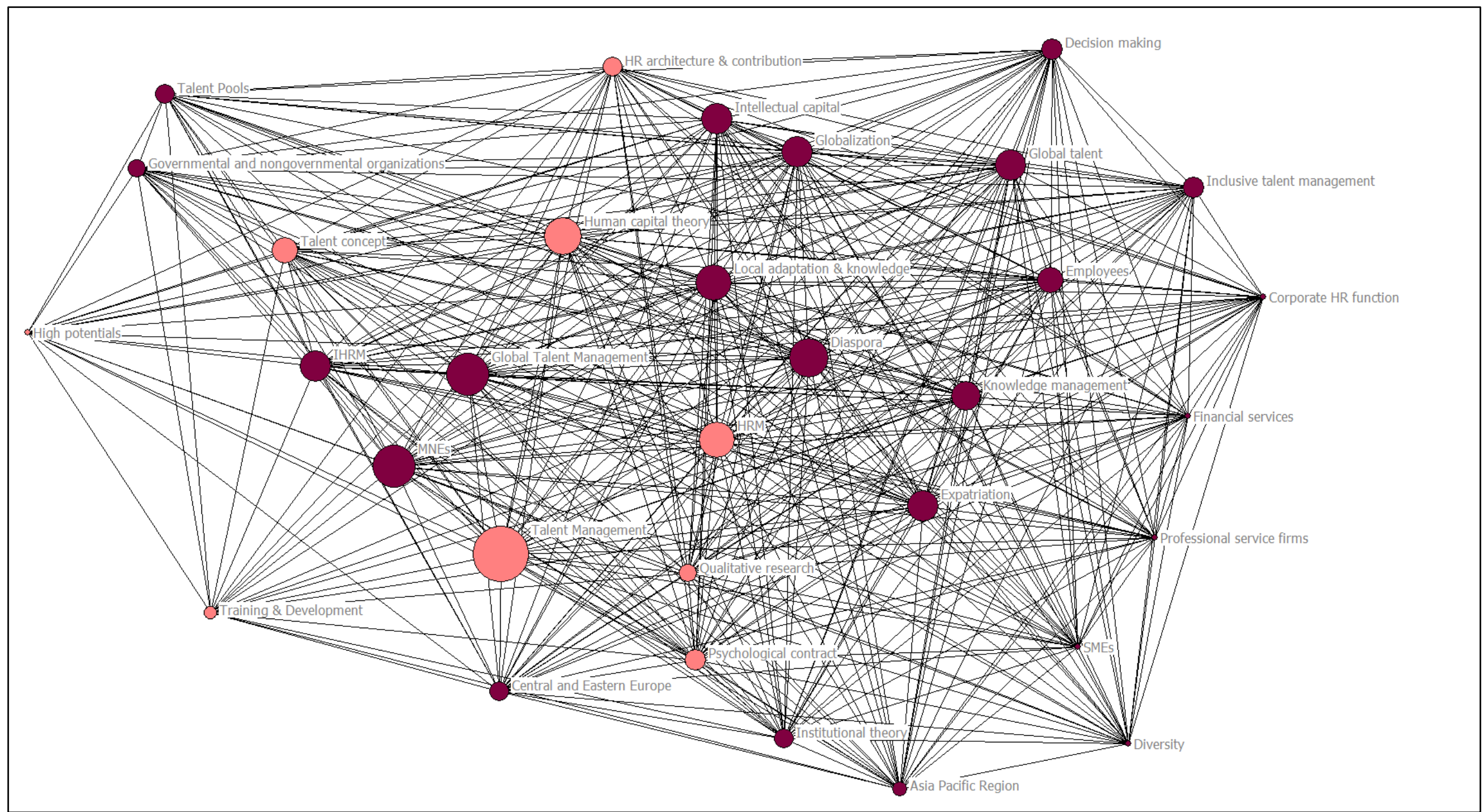

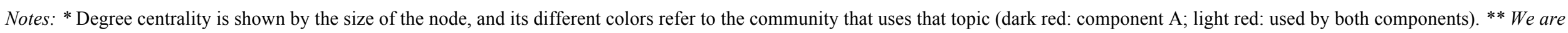
only considering nodes with degree above 30, which is half the total grade (61). 
Fig. 13 Subset of most central topics within component B (N=24)

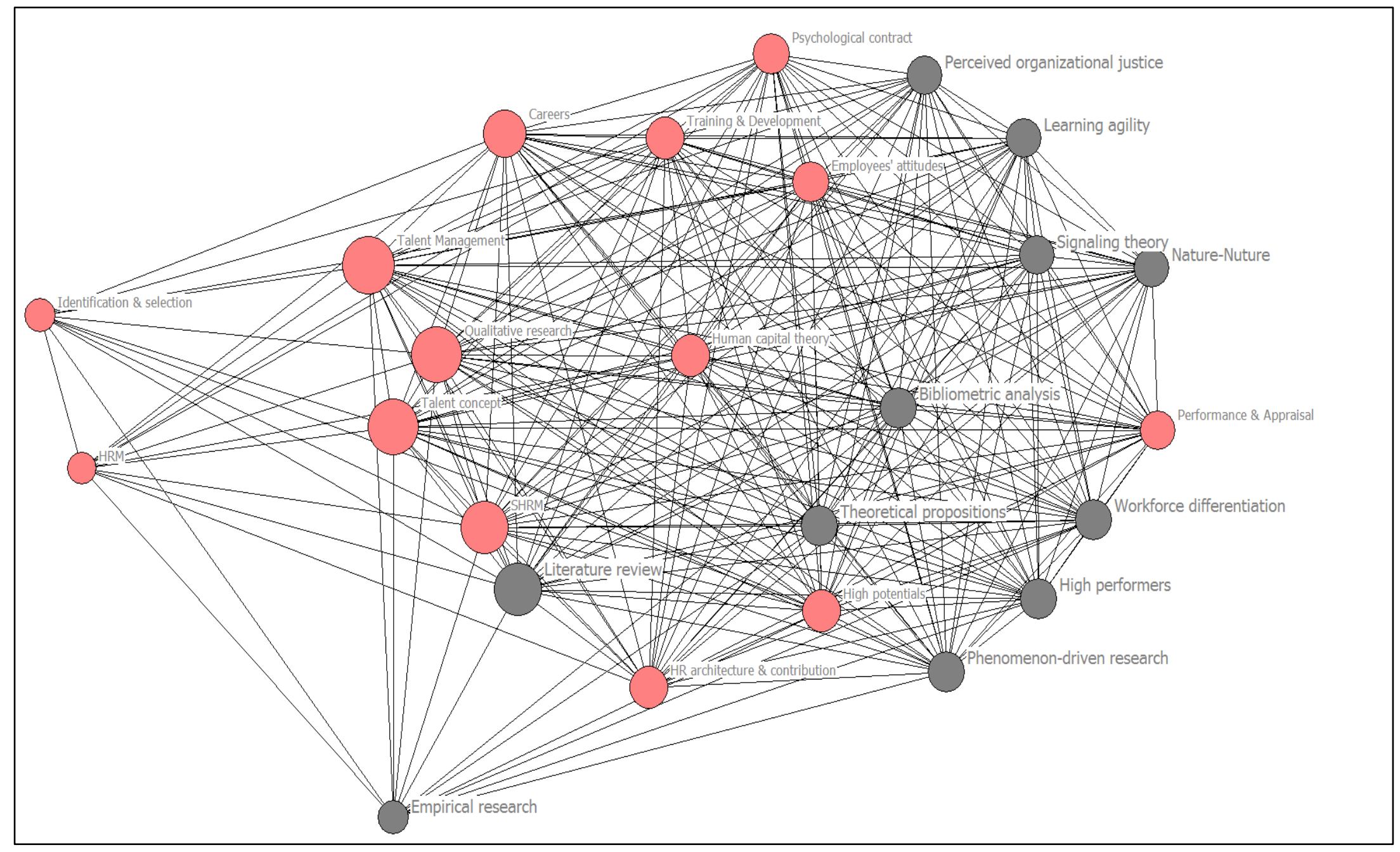

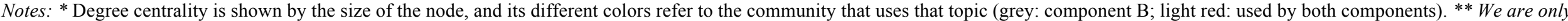
considering nodes with degree above 16, which is half the total grade (32). 
Table 3 Authors' Ranking based on centrality metrics*' $(\mathrm{N}=494)$

\begin{tabular}{|lllll|}
\hline Rank & Author & Freeman Degree & Author & Betwenness \\
\hline 1 & Dries, N. & 25 & Duarte, M.E. & 25787 \\
\hline 2 & Scullion, H. & 22 & Lopes, J.A. & 24554 \\
\hline 3 & Farndale, E. & 14 & Björkman, I. & 4598 \\
\hline 4 & Björkman, I. & 13 & Dries, N. & 3000 \\
\hline 5 & Pepermans, R. & 11 & Gallardo-Gallardo, E. & 2677 \\
\hline 6 & Collings, D. G. & 10 & Barkhuizen, N. & 2193 \\
\hline 7 & Iles, P. & 10 & Feisel, E. & 2187 \\
\hline 8 & McDonnell, A. & 10 & Kim, S. & 1897 \\
\hline 9 & Sparrow, P. & 10 & Daraei, M. R. & 1753 \\
\hline 10 & Stiles, P. & 10 & Donnellan, B. & 1750 \\
\hline 11 & Gallardo-Gallardo, E. & 9 & Aziz, A.A. & 1747 \\
\hline 12 & Gelens, J. & 9 & Lamare, R. & 1747 \\
\hline 13 & Hofmans, J. & 9 & Lancaric, D. & 1744 \\
\hline 14 & Preece, D. & 9 & Gelens, J. & 1730 \\
\hline 15 & Vance, C. M. & 9 & Brewster, C. & 1677 \\
\hline 16 & Barkhuizen, N. & 8 & Cerdin, J.-L. & 1527 \\
\hline 17 & Gunnigle, P. & 8 & Berry, W. R. & 1323 \\
\hline 18 & Schuler, R. S. & 8 & Craig, E. & 1321 \\
\hline 19 & Schutte, N. & 8 & Hartmann, E. & 1316 \\
\hline 20 & Thunnissen, M. & 8 & Bracco, A. & \\
\hline & & & & \\
\hline
\end{tabular}

Note: ${ }^{*}$ We also tested Eigenvector centrality, which measures popularity weighting the importance of each author/node according to how 'popular' or 'well connected' their connections are. While eigenvalues allow for the identification of "popular" actors, it is not adding useful information regarding the identification of key players in our co-authorship TM network, because they also highlight those that despite not being central are connected to the referential ones. 
Fig. 4 Most central authors according to Freeman degree

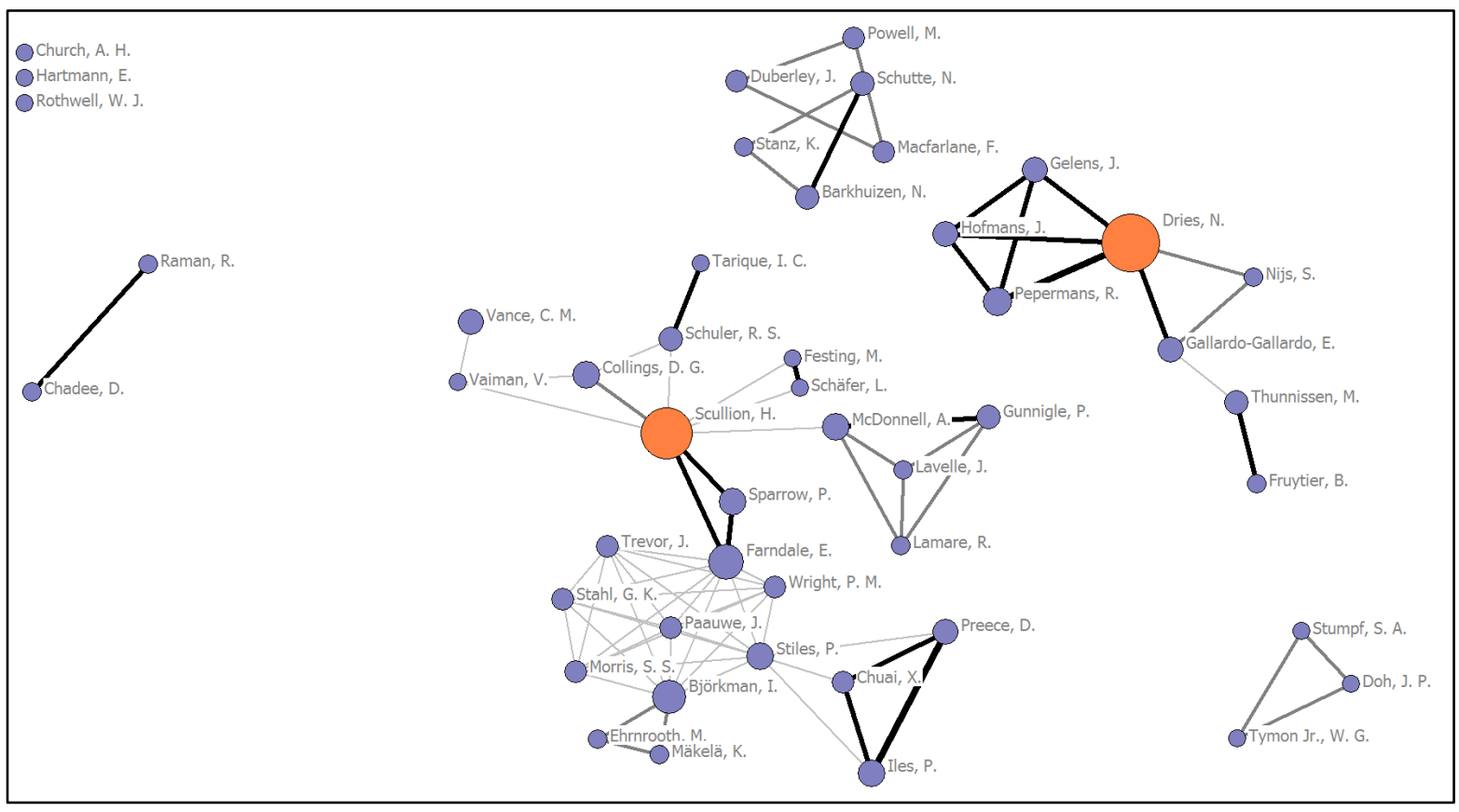


Fig. 5 Authors acting as cutpoints

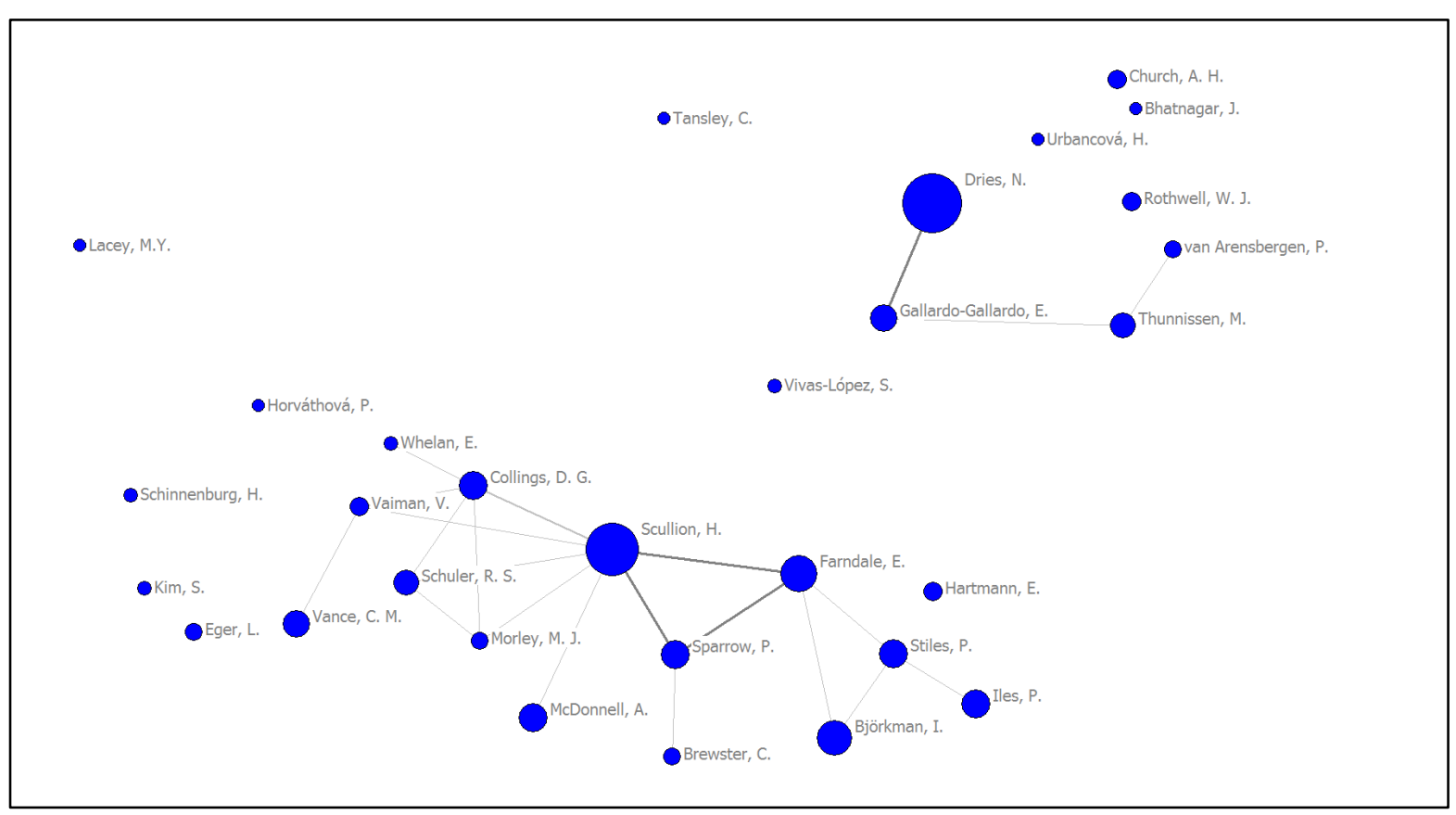


Fig. 6 Core components of collaboration in TM research

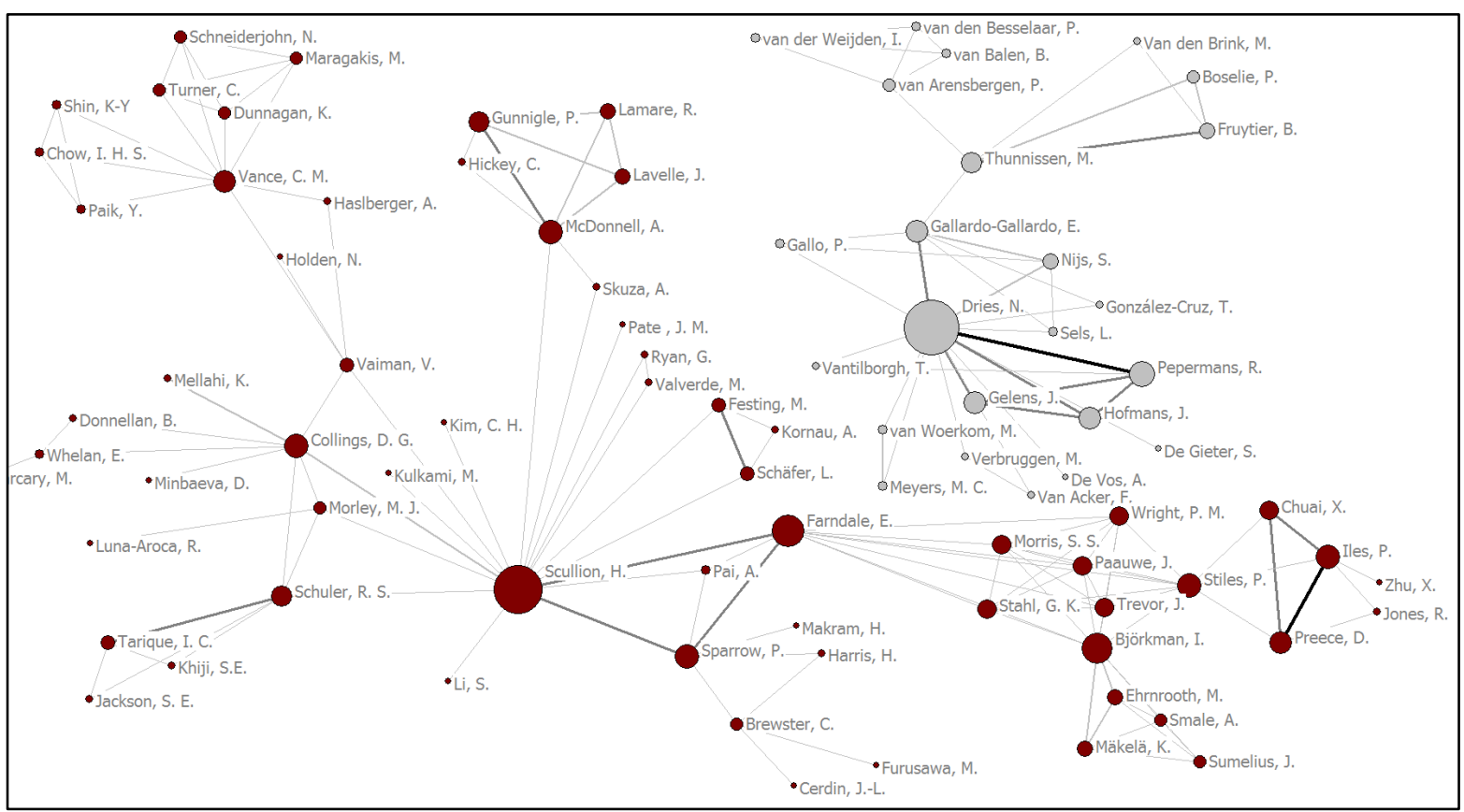

Note: The thickness of the tie represents the intensity of the link (collaborations between two actors). The node size is set according to Freeman degree (total number of links per author) 
Table 4 Top 5 key authors of the core of TM collaboration network

\begin{tabular}{|c|c|c|c|}
\hline & Freeman Degree & Betweenness & Eigenvector \\
\hline $\begin{array}{l}\text { Overall network } \\
(\mathrm{N}=87)\end{array}$ & $\begin{array}{l}\text { Scullion, H. } \\
\text { Dries, N. } \\
\text { Björkman, I. } \\
\text { Farndale, E. } \\
\text { Stiles, P. }\end{array}$ & $\begin{array}{l}\text { Scullion, H. } \\
\text { Dries, N. } \\
\text { Farndale, E. } \\
\text { Vaiman, V. } \\
\text { Vance, C. M. }\end{array}$ & $\begin{array}{l}\text { Björkman, I. } \\
\text { Farndale, E. } \\
\text { Stiles, P. } \\
\text { Morris, S. S. } \\
\text { Paauwe, J. }\end{array}$ \\
\hline Component $\mathrm{A}(\mathrm{N}=63)$ & $\begin{array}{l}\text { Scullion, H. } \\
\text { Björkman, I. } \\
\text { Farndale, E. } \\
\text { Stiles, P. } \\
\text { Vance, C. M. }\end{array}$ & $\begin{array}{l}\text { Scullion, H. } \\
\text { Farndale, E. } \\
\text { Vaiman, V. } \\
\text { Vance, C. M. } \\
\text { Collings, D. G. }\end{array}$ & $\begin{array}{l}\text { Björkman, I. } \\
\text { Farndale, E. } \\
\text { Stiles, P. } \\
\text { Morris, S. S. } \\
\text { Paauwe, J. }\end{array}$ \\
\hline Component $\mathrm{B}(\mathrm{N}=24)$ & $\begin{array}{l}\text { Dries, N. } \\
\text { Gallardo-Gallardo, E. } \\
\text { Thunnissen, M. } \\
\text { van Arensbergen, P. } \\
\text { Pepermans, R. }\end{array}$ & $\begin{array}{l}\text { Dries, N. } \\
\text { Gallardo-Gallardo, E. } \\
\text { Thunnissen, M. } \\
\text { van Arensbergen, P. } \\
\text { Pepermans, R. }\end{array}$ & $\begin{array}{l}\text { Indifference in } \\
\text { eigenvector centrality, all } \\
\text { actors with high levels of } \\
\text { popularity are in the } \\
\text { component A }\end{array}$ \\
\hline
\end{tabular}


Fig. 7 Visualization of Component A network by gender, degree and country

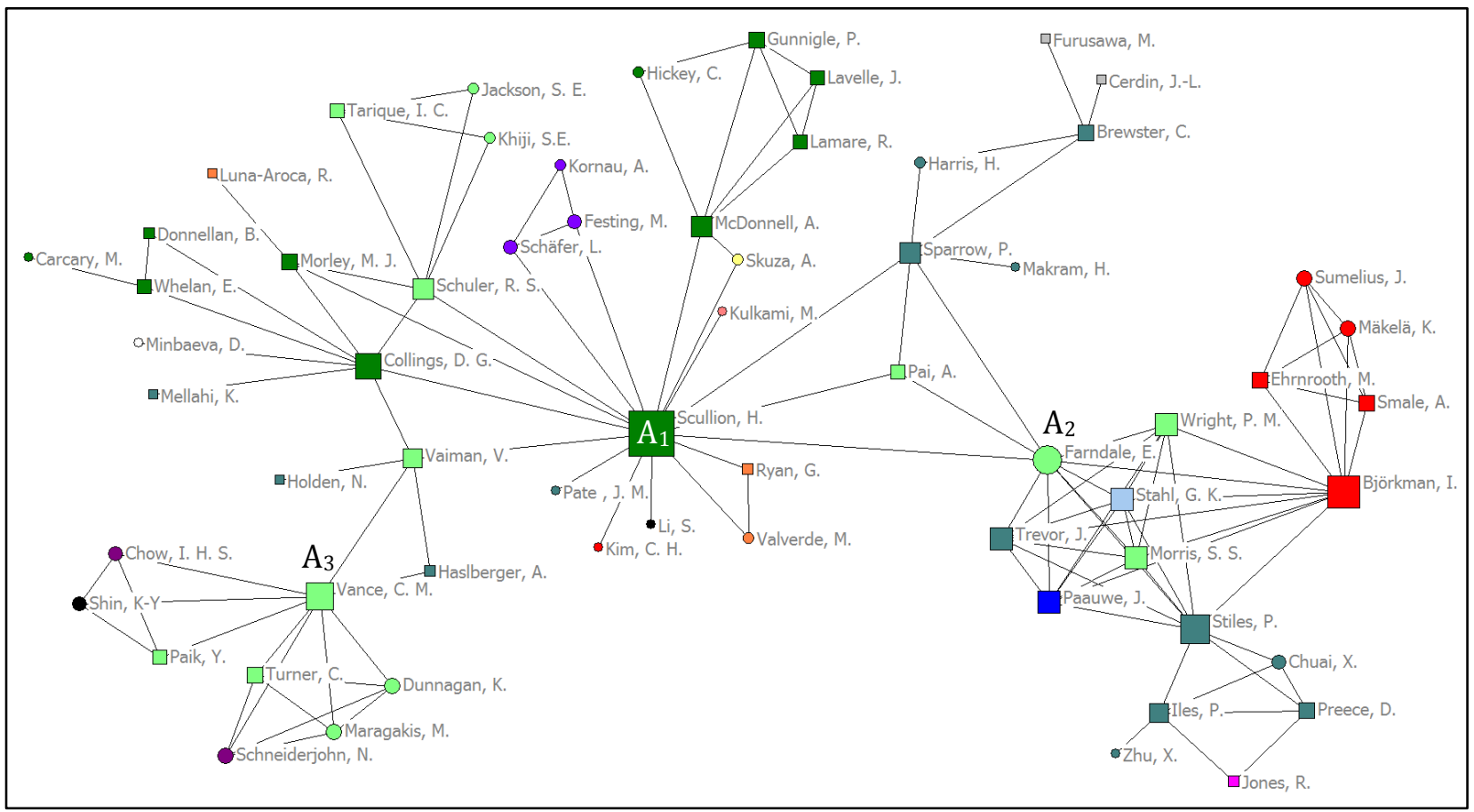

Note: Circles represent women, whereas squares represent men. Degree is shown by the size of the node, and its different color refers to the country. 
Fig. 8 Visualization of Component A network by gender, degree and research area

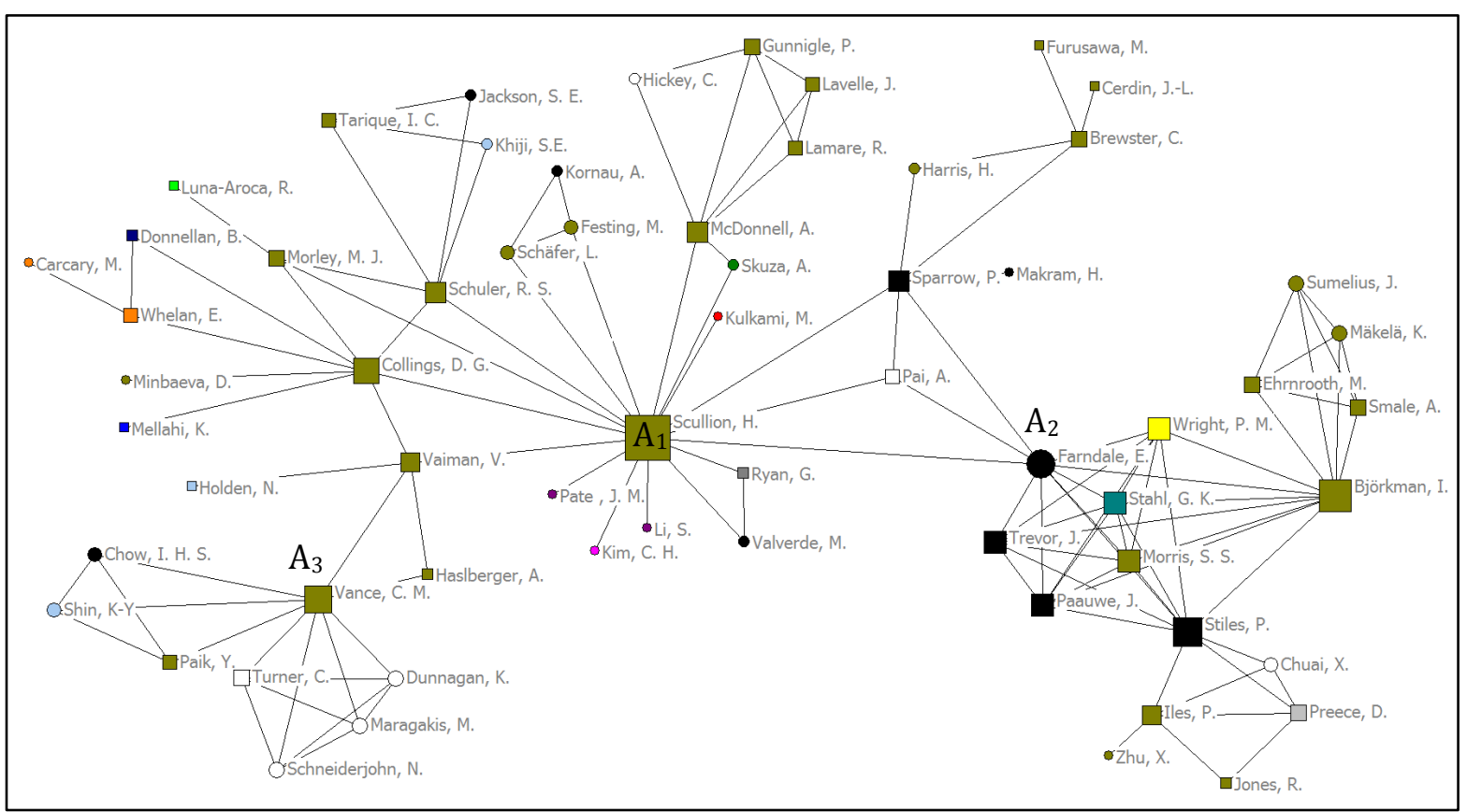

Note: Circles represent women, whereas squares represent men. Degree is shown by the size of the node, and its different color refers to the research area (IHRM = bottle green; HRM = black; non-academics = white). 
Fig. 9 Visualization of Component $\mathbf{B}$ network by gender, degree and country

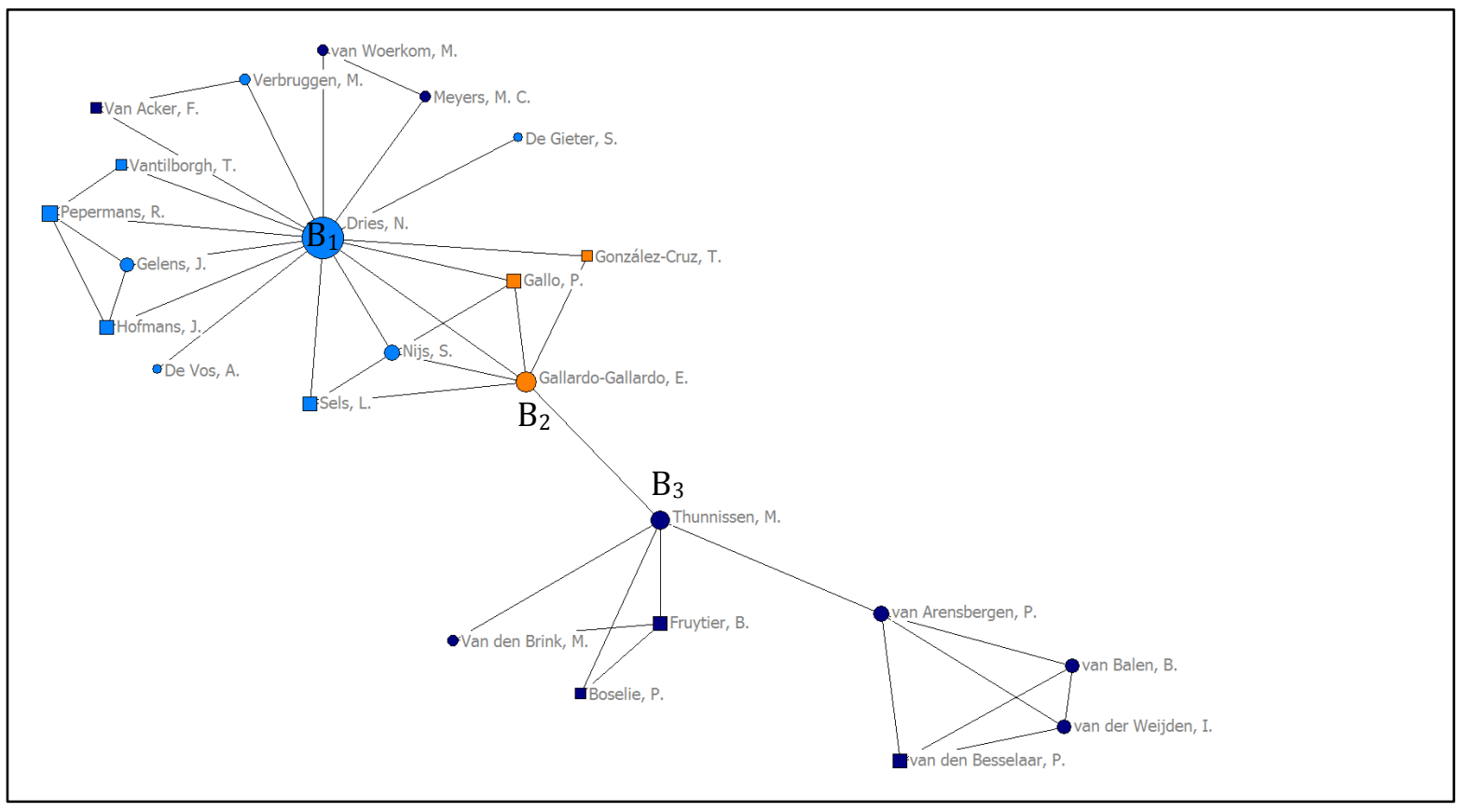

Note: Circles represent women, whereas squares represent men. Degree is shown by the size of the node, and colors represent different countries. 
Fig. 10 Visualization of Component B network by gender (shape), degree (node size) research area (color)

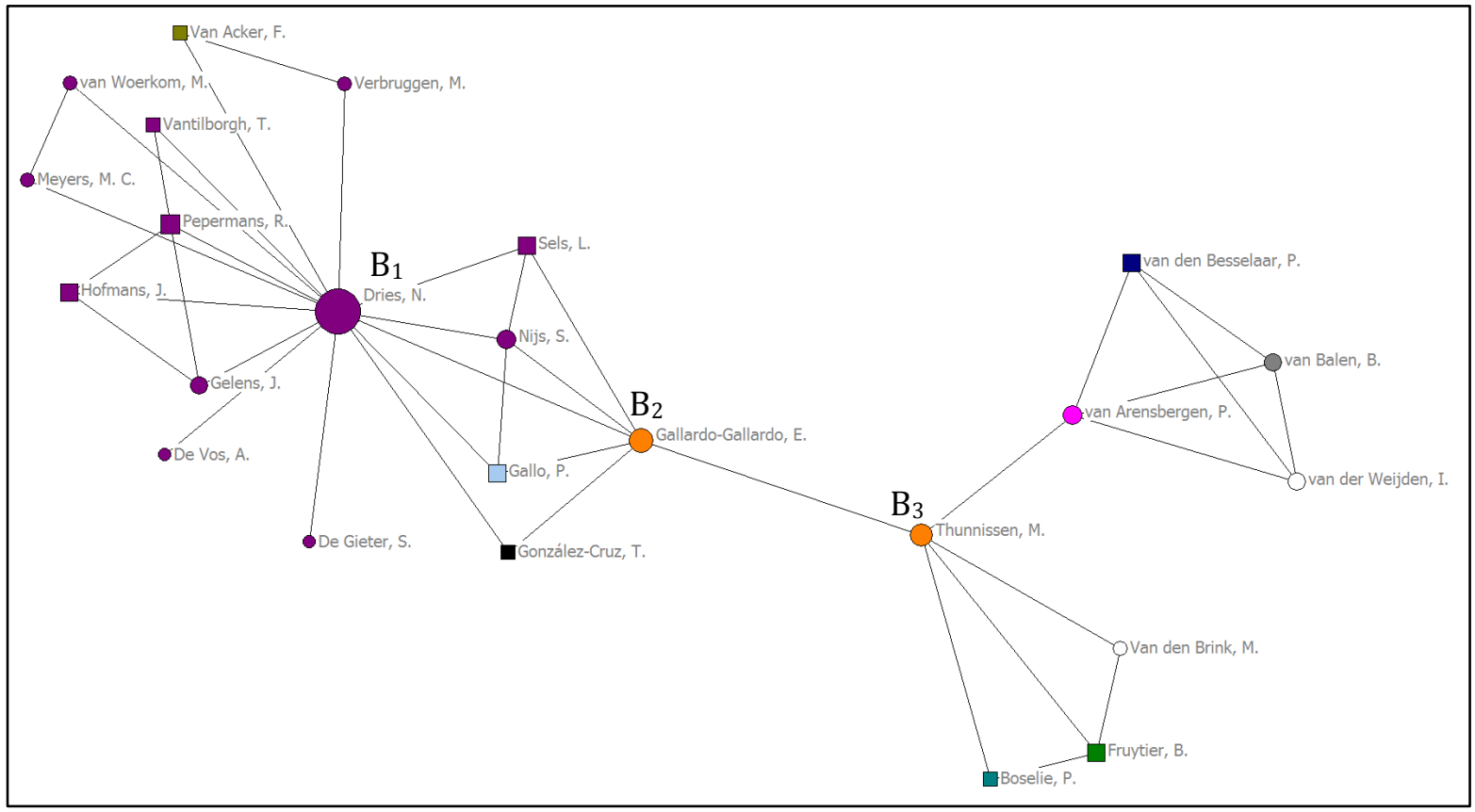

Note: Circles represent women, whereas squares represent men. Degree is shown by the size of the node, and its different color refers to the research area (Organizational Psychology = purple; HRM = orange). 
Fig. 11 The most 40 central nodes in the TM research network $(N=79)$

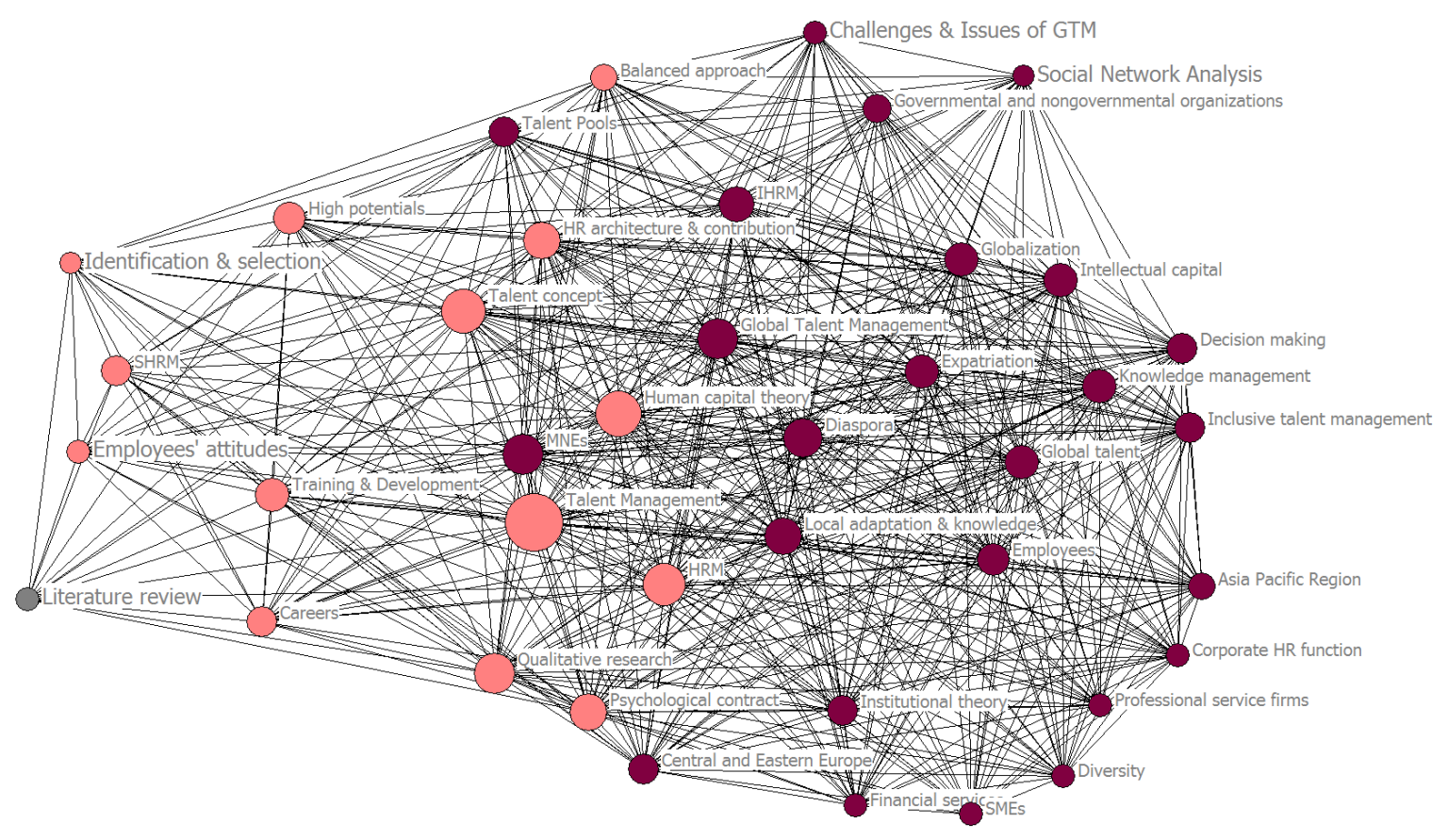

Note: Degree centrality is shown by the size of the node, and its different colors refer to the community that uses that topic (dark red: component A; grey: component B; light red: used by both components) 
Table 5 Top key topics within each component

\begin{tabular}{|c|c|c|}
\hline & Component A & Component B \\
\hline 2005 & $\begin{array}{l}\text { HR Architecture } \\
\text { IHRM }\end{array}$ & - \\
\hline 2008 & $\begin{array}{l}\text { Asia Pacific Region } \\
\text { HRM } \\
\text { MNEs } \\
\text { Training \& Development } \\
\text { Governmental and NGOs }\end{array}$ & - \\
\hline 2009 & $\begin{array}{l}\text { Talent Management } \\
\text { HR architecture \& contribution } \\
\text { Talent Pools } \\
\text { Performance Outcomes } \\
\text { Pivotal Talent Positions }\end{array}$ & - \\
\hline 2011 & $\begin{array}{l}\text { Global Talent Management } \\
\text { HRM } \\
\text { MNEs } \\
\text { Talent Pools } \\
\text { Training \& development } \\
\text { Human capital theory } \\
\text { Talent concept } \\
\text { Global talent } \\
\text { Identification\& selection } \\
\text { SHRM } \\
\text { Case study research } \\
\text { Challenges \& Issues of GTM } \\
\text { War of talent }\end{array}$ & - \\
\hline 2012 & $\begin{array}{l}\text { Talent Management } \\
\text { HRM }\end{array}$ & $\begin{array}{l}\text { Careers } \\
\text { Talent Management } \\
\text { High Potentials }\end{array}$ \\
\hline 2013 & $\begin{array}{l}\text { Talent Management } \\
\text { Global Talent Management } \\
\text { MNEs } \\
\text { Careers } \\
\text { Central and Eastern Europe }\end{array}$ & $\begin{array}{l}\text { Talent Management } \\
\text { Careers } \\
\text { High Potentials } \\
\text { Nature-Nurture } \\
\text { Workforce differentiation }\end{array}$ \\
\hline 2014 & $\begin{array}{l}\text { Talent Management } \\
\text { Global Talent Management } \\
\text { Talent concept } \\
\text { Diaspora } \\
\text { Psychological contract }\end{array}$ & $\begin{array}{l}\text { Talent Concept } \\
\text { Talent Management } \\
\text { SHRM }\end{array}$ \\
\hline 2015 & $\begin{array}{l}\text { Local adaptation \& Knowledge } \\
\text { Diversity } \\
\text { Value concept }\end{array}$ & $\begin{array}{l}\text { Talent Management } \\
\text { Identification \& Selection } \\
\text { Literature review }\end{array}$ \\
\hline 2016 & $\begin{array}{l}\text { MNEs } \\
\text { Talent Pools } \\
\text { Local adaptation \& Knowledge } \\
\text { SHRM } \\
\text { Ireland }\end{array}$ & $\begin{array}{l}\text { Talent Management } \\
\text { Talent Concept }\end{array}$ \\
\hline
\end{tabular}

